\title{
The effects of oil price shocks on stock market volatility: Evidence from European data
}

\author{
Stavros Degiannakis ${ }^{1}$, George Filis ${ }^{2} *$, Renatas Kizys ${ }^{3}$ \\ ${ }^{1,3}$ University of Portsmouth \\ Department of Economics \\ Richmond Building, Portland Street, PO1 3DE \\ Portsmouth, UK \\ ${ }^{2}$ Bournemouth University \\ Department of Accounting, Finance and Economics \\ Executive Business Centre, \\ 89 Holdenhurst Road, BH8 8EB \\ Bournemouth, UK
}

*corresponding author: gfilis@bournemouth.ac.uk, tel:+44 1202968739 , fax:+44 1202968833

The paper investigates the effects of oil price shocks on stock market volatility in Europe by focusing on three measures of volatility, i.e. the conditional, the realized and the implied volatility. The findings suggest that supply-side shocks and oil specific demand shocks do not affect volatility, whereas, oil price changes due to aggregate demand shocks lead to a reduction in stock market volatility. More specifically, the aggregate demand oil price shocks have a significant explanatory power on both current- and forwardlooking volatilities. The results are qualitatively similar for the aggregate stock market volatility and the industrial sectors' volatilities. Finally, a robustness exercise using short- and long-run volatility models supports the findings.

JEL: C13, C32, G10, G15, Q40

Keywords: Conditional Volatility, Realized Volatility, Implied Volatility, Oil Price Shocks, SVAR

\section{INTRODUCTION AND BRIEF REVIEW OF THE LITERATURE}

There is a consensus among academics and practitioners that oil and stock markets are often intertwined with the global economic activity. Ascertaining exact nature and sources of the linkage between oil and stock markets and the global economic activity has proved to be a promising area for researchers over the last few decades. The research interest mainly concentrates either on the impact of oil prices on stock market developments or the effects of oil prices on the economy. Adding to this literature, the main objective of the paper is to research into the effects of three oil price shocks (namely, supply side shocks, aggregate demand shocks and oil specific demand shocks) on stock market volatility, with particular reference in the European stock market.

The seminal paper by Jones and Kaul (1996) was among the first to reveal a negative relationship between the oil prices and stock market returns. In addition, Sadorsky (1999) concludes that oil price changes are important determinants of stock market returns. In particular, he shows that stock markets respond negatively to a positive oil price change. Filis (2010), Chen (2009), Miller and Ratti (2009), Park and Ratti (2008), Driesprong et al. (2008) and Gjerde and Sættem (1999) second these findings by Sadorsky (1999) and Jones and Kaul (1996). 
The aforementioned negative relationship does not hold for stock markets operating in oil-exporting countries. Arouri and Rault (2012) show that for the oil-exporting countries, there is a positive relationship between oil price shocks and stock market returns. Other authors, though, do not find any relationship between oil price shocks and stock market returns (Jammazi and Aloui, 2010; Cong et al., 2008; Haung et al., 1996). Filis et al. (2011) provide an extensive review of the literature in the particular area.

Studies particularly focused on the European stock markets reveal that positive oil price changes tend to negatively affect stock returns; nevertheless, the exact relationship depends on the sector. In particular, oil-related stock market sectors tend to appreciate in the event of a positive oil price change, whereas the reverse holds for oil-intensive sectors (see, for example, Scholtens and Yurtsever, 2012; Arouri, 2011; Arouri and Nguyen, 2010).

Furthermore, a strand of the literature distinguishes the effects of oil price shocks on stock market activity according to their origin. Hamilton (2009a,b) and Kilian (2007a,b), in particular, suggest that different shocks in the oil market have different effects on stock markets. Kilian (2009) provides evidence that the response of aggregate stock returns differs depending on the cause of the oil price shock. Hamilton $(2009 a, b)$ disaggregates oil price shocks into two components, namely, the demand-side oil price shocks (which are caused by increased aggregate demand, e.g. due to the industrialization of China) and supply-side oil prices shocks (which are caused by alteration in the world oil production). In addition, Kilian (2009) identifies a third origin, the precautionary demand shocks or oil specific demand shocks. These are oil price shocks that are related with the uncertainty of the future availability of oil.

Baumeister and Peersman (2012), Basher et al. (2012), Kilian and Lewis (2011), Filis et al. (2011), Lippi and Nobili (2012), Kilian and Park (2009), Apergis and Miller (2009), Lescaroux and Mignon (2008), Kilian (2008) and Barsky and Kilian (2004) also illustrate the importance of taking into consideration the origins of the oil price shock in this area of interest. For example, Hamilton $(2009$ a,b) maintain that oil price shocks are mainly demand driven in the last decades and thus supply-side events do not exercise significant effects in oil prices. Lippi and Nobili (2012) proponent that supply-side oil price shocks have a negative effect in the economy, whereas the opposite is observed for the demand-side oil price shocks. In addition, Kilian and Park (2009) demonstrate that the supply-side oil price shocks do not have any effects on stock market returns, whereas stock markets tend to react negatively to oil specific demand shocks. On the other hand, they find that aggregate demand oil price shocks trigger a positive response from the stock markets. In the same line of reasoning, Filis et al. (2011) find evidence that the supply-side shocks do not seem to impact stock market returns, whereas the reverse holds for the demandside shocks. Similarly, Basher et al. (2012) show that supply-side oil price shocks do not exercise an impact on the emerging stock market returns, whereas the aggregate demand oil price shocks seem to have a positive effect. Finally, they find evidence that the oil specific demand shocks put downward pressure on stock returns.

Despite the fact that evidence proposes that the origin of the oil price shock triggers different responses from the stock markets, the majority of the literature does not consider them when examines its effects (see, inter alia, Arouri and Rault, 2012; Arouri and Nguyen, 2010; Bjørnland, 2009; Chen, 2009; Park and Ratti, 2008).

As aforementioned, the aim of this paper is to direct the attention of the research on the effects of the oil price shocks on stock market volatility. Studies in the early 80s and 90s (see, for example, Pindyck, 1991 and Bernanke, 1983, among others) reveal that increased energy prices generate uncertainty to firms, resulting in the delay of investment decisions. Furthermore, some authors opine 
that oil price innovations exercise an impact on aggregate uncertainty and they have significant negative effects on investments (see, inter alia, Ratti et al., 2011; Rahman and Serletis, 2011; Elder and Serletis, 2010). In addition, Bloom (2009) documents that stock market uncertainty increases after major shocks, such as the 2001 terrorist attack in US, OPEC oil supply disruptions, etc. Nevertheless, these studies have not considered the origins of the oil price shocks. We argue, though, that Bloom's choice of major shocks coincides with events that trigger certain oil price shocks, as these have been identified by Hamilton (2009a,b) and Kilian (2009, 2007a,b). For example, the 2001 terrorist attack in US triggered an oil specific demand shock, whereas OPEC oil supply disruptions cause supply-side oil price shocks. Thus, disentangling oil price shocks is of importance in understanding better stock market uncertainty.

In addition, the literature has well established that the aforementioned firm's uncertainty and aggregate uncertainty can be represented by individual stock price volatility and stock market volatility, respectively (see, for example, Baum et al., 2010 and Bloom, 2009).

Even though the characteristics of stock market volatility have been studied extensively in the past, ${ }^{1}$ the literature remains silent on the effects of the different oil price shocks on stock market volatility. Rather, a plethora of research output centers its attention solely on spillover effects between the oil price volatility and stock market returns and volatility or the relationship between oil price volatility and firm investments. ${ }^{2}$ This paper comes to fill this void.

More specifically, the contribution of the paper is threefold. First, it contributes to the literature that studies the effects of three different oil price shocks - oil supply shock, aggregate demand shock and oil specific demand shock $^{3}$ - on the stock market. Unlike previous studies that examine the response of stock returns on oil price shocks, we investigate the response of stock market volatility, as a measure of uncertainty of stock market investments, using a Structural VAR model. Second, we provide evidence from both aggregate stock market indices and industrial sector indices, as according to Arouri et al. (2012, p.2) "the use of equity sector indices is, in our opinions, advantageous because market aggregation may ask the characteristics of various sectors". Third, in contrast to studies that mainly focus on the responses of stock market returns in individual countries in Europe or in the US (Arouri, 2011; Arouri and Nguyen, 2010 and Scholtens and Yurtsever, 2012 are notable exceptions), emphasis of this research is placed on the pan-European stock market.

In light of empirical evidence that underlines the relative importance of the demand-driven oil price shocks, we expect stock market volatility in Europe to be more sensitive to the aggregate demand shock and the oil specific demand shock than to the supply-side shock.

Three volatility measures are utilized; conditional volatility, realized volatility and implied volatility. The conditional volatility, estimated from a predefined ARCH model, is the most widely applied method of quantifying volatility in financial time series. The realized volatility, introduced by Andersen and Bollerslev (1998), sums the high frequency squared log-returns to generate a lower frequency volatility measure. According to Ebens (1999), among others, the use of high frequency data for computing volatility at a lower frequency provides more accurate estimates of volatility. Implied volatility derives from the option pricing.

\footnotetext{
${ }^{1}$ See, among others, Xekalaki and Degiannakis (2010), Becker et al. (2007), Andersen et al. (2005a), Andersen et al. (2001) and Bollerslev et al. (1992).

${ }^{2}$ See, inter alia, Arouri et al. (2012), Henriques and Sadorsky (2011), Sadorsky (2011), Arouri et al. (2011), Vo (2011), Malik and Ewing (2009), Chiou and Lee (2009).

${ }^{3}$ Definitions of these shocks can be found in Kilian and Park (2009).
} 
The conditional volatility was chosen because it is the most generally applied measure of variance. The use of realized volatility measure is justified by the recent findings in financial literature that it provides more accurate estimates of volatility. On the other hand, the use of implied volatility is motivated by the fact that part of the literature illustrates that this type of volatility (a forward-looking measure) is more informational efficient compared to other volatility estimates, which represent the current-looking measures of volatility. ${ }^{4}$

Thus, it is important to identify any differences in their responses to oil price shocks. Koopman et al. (2005) propose that both implied volatility and realized volatility are informationally accurate. Conversely, authors such as Becker et al. (2007) and Corrado and Truong (2007) suggest that implied volatility indices do not provide any incremental information compared to other volatility indices. Engle (2002), though, argues that there is not a simple answer as to which volatility measure is the most accurate, as it depends upon the statistical approach adopted for the evaluation of forecasts.

We provide evidence that supply-side shocks and oil specific demand shocks do not affect stock market volatility, whereas, oil price changes due to aggregate demand shocks lead to a reduction in stock market volatility. The results hold for the industrial sectors' volatilities, as well. Prominent among our results is the finding that oil price shocks have a qualitatively similar impact for both the current-looking volatility measures and the implied volatility, which is a forward-looking measure.

The rest of the paper is organized as follows: Section 2 presents the volatility measures and the model used, Section 3 describes the dataset, Section 4 presents the empirical findings of the research and Section 5 concludes the study.

\section{METHODOLOGY}

In the next section three measures of volatility are defined, i.e. conditional volatility, realized volatility and implied volatility, whereas in section 2.2 the Structural VAR model is presented.

\subsection{Volatility Estimates}

According to the literature there are three main frameworks for measuring volatility. The first two correspond to the current market volatility measures, whereas the third is a forward-looking measure of volatility. In this paper we examine all these three volatility estimates.

The conditional volatility is the conditional standard deviation of the asset returns given the most recently available information. The conditional variance process of $y_{t}$ can be defined as $V\left(y_{t} \mid I_{t-1}\right) \equiv V_{t-1}\left(y_{t}\right) \equiv \sigma_{t}^{2}$, for $I_{t-1}$ denoting the information set investors know when they make their investment decisions at time $t-1$.

The realized volatility is based on the idea of using high frequency data to compute measures of volatility at a lower frequency, i.e. using hourly logreturns to generate a measure of daily volatility. By the term monthly realized volatility we denote the daily estimate of monthly variance.

Implied volatility is the instantaneous standard deviation of the return on the underlying asset, which would have to be input into a theoretical pricing model in order to yield a theoretical value identical to the price of the option in the marketplace, assuming all other inputs are known.

\footnotetext{
${ }^{4}$ See for example Blair et al. (2001), Christensen and Prabhala (1998), Fleming (1998) and Day and Lewis (1992).
} 


\subsubsection{Conditional Volatility}

The conditional variance of the daily log-returns process, $y_{t}$, is estimated with Ding's et al. (1993) APARCH model. The APARCH model has an appealing feature that it allows nesting tests of different types of asymmetry and functional forms (Hentschel, 1995). For instance, Laurent (2004) argues that the APARCH model nests at least seven GARCH specifications. The asymmetric power ARCH, or APARCH model is estimated assuming that the demeaned daily log-returns are conditionally Student-t distributed: ${ }^{5}$

$$
\begin{gathered}
y_{t}=c_{0}+\varepsilon_{t} \\
\varepsilon_{t}=\sigma_{t} z_{t} \\
\sigma_{t}^{\delta}=a_{0}+a_{1}\left(\left|\varepsilon_{t-1}\right|-\gamma_{1} \varepsilon_{t-1}\right)^{\delta}+b_{1} \sigma_{t-1}^{\delta} \\
z_{t}^{\text {i.i.d. }} \sim T(0,1 ; v) \\
f_{(t)}\left(z_{t} ; v\right)=\frac{\Gamma((v+1) / 2)}{\Gamma(v / 2) \sqrt{\pi(v-2)}}\left(1+\frac{z_{t}^{2}}{v-2}\right)^{-\frac{v+1}{2}},
\end{gathered}
$$

where $a_{0}>0, \delta>0, b_{1} \geq 0, a_{1} \geq 0$ and $-1<\gamma_{1}<1, v>2$.

The APARCH model with Student-t distributed standardized innovations accounts for i) volatility clustering, ii) power transformation of the conditional variance, iii) asymmetric and leptokurtic unconditional distribution of log-returns, and iv) asymmetric conditional distribution of log-returns. Therefore, it is considered as of the most successfully applied model in estimating conditional volatility. For technical details, the reader is referred to Xekalaki and Degiannakis (2010).

The monthly conditional volatility is computed by summing the $\tau$ daily conditional variance. Therefore, the annualized conditional volatility of month $t$, or $C V_{t}^{(m)}$, is computed as the square root of the sum of the conditional variances from the $16^{\text {th }}$ of the previous month up to and including the 15 th of the current month: ${ }^{6}$

$$
C V_{t}^{(m)}=100 \sqrt{12 \sum_{j=1}^{\tau} \sigma_{t_{j}}^{2}}
$$

where $\sigma_{t_{j}}^{2}$ denotes the daily conditional variance for the $j=1, \ldots, \tau$ trading days of month $t$.

\subsubsection{Realized Volatility}

Merton (1980) was the first who noted the idea of using high frequency data to compute measures of volatility at a lower frequency. The concept of the realized volatility is based on the integrated volatility, $\sigma_{[a, b]}^{2(I V)}=\int_{a}^{b} \sigma^{2}(t) d t$. Financial literature assumes that the instantaneous logarithmic price, $\log p(t)$,

\footnotetext{
${ }^{5}$ The incorporation of a first-order autoregressive term, AR(1), in the conditional mean, provides qualitative similar results.

${ }^{6}$ The use of the daily observations from the $16^{\text {th }}$ of the previous month up to the $15^{\text {th }}$ of the current month is justified by the availability of the monthly data on the $15^{\text {th }}$ of each month.
} 
of a financial asset follows a diffusion process, $d \log p(t)=\sigma(t) d W(t)$, where $\sigma(t)$ is the volatility of the instantaneous log-returns process and $W(t)$ is the standard Wiener process. Theory of quadratic variation of semi-martingales provides consistent estimate of integrated volatility by the realized variance,

$R V_{[a, b]}=\sum_{j=1}^{\tau}\left(\log P_{t_{j}}-\log P_{t_{j-1}}\right)^{2}$, assuming that the time interval $[a, b]$ is partitioned in $\tau$ equidistance points in time; see Andersen et al. (2003) and Barndorff-Nielsen and Shephard (2002).

For present study's purposes we measure the monthly realized volatility, partitioning the monthly time interval in daily equidistance points in time, for $\tau$ denoting the number of trading days. Therefore, the annualized realized volatility of month $t$, or $R V_{t}^{(m)}$, is computed as the square root of the sum of the squared daily log-returns from the 16th of the previous month up to the 15 th of the current month:

$$
R V_{t}^{(m)}=100 \sqrt{12 \sum_{j=1}^{\tau}\left(\log P_{t_{j}}-\log P_{t_{j-1}}\right)^{2}} .
$$

We estimate monthly volatility by summing up daily volatility. However, this measure would be biased by the number of trading days in the month. That is, volatility in the month with more trading days would be greater than volatility in any other month, even the volatility does not change. In order to check the robustness of the results, we also estimate $R V_{t}^{(m)}$ by scaling each month's volatility with $\sqrt{22 / \tau}$, assuming equal number of trading days for each month. The results remain qualitatively similar.

\subsubsection{Implied Volatility Index - VSTOXX}

Studies, see i.e. Blair et al. (2001), characterize implied volatility measures are less informative than volatility estimated from asset returns, because they induce biases and contain mis-specification problems. In 1993, the Chicago Board of Options Exchange published the first implied volatility index. The computation of implied volatility indices takes into account the latest advances in financial theory, eliminating measurement errors that had characterized the implied volatility measures.

Market participants consider the implied volatility index as an important tool for measuring investors' sentiment. Investors and risk managers refer to volatility indices as fear index or investor fear gauge. The VSTOXX Volatility Index (which is the volatility index for the Eurostoxx 50 Index, also named as EURO STOXX 50 Volatility Index) measures the implied variance across all options of a given time to expiry. The main index is designed as a rolling index at a fixed 30 days to expiry. This is achieved using linear interpolation of the two nearest of the eight available sub-indices. The index is calculated based on eight expiry months with a maximum time to expiry of two years.

The annualized implied volatility of month $t$, or $\operatorname{VSTOXX} X_{t}^{(m)}$, is computed as the average of the daily $\operatorname{VSTOXX}{ }_{t_{j}}$ from the $16^{\text {th }}$ of the previous month up to the $15^{\text {th }}$ of the current month:

$$
\operatorname{VSTOXX}_{t}^{(m)}=\sqrt{\tau}^{-1} \sqrt{\sum_{j=1}^{\tau} \operatorname{VSTOXX}_{t_{j}}^{2}}
$$


where $\operatorname{VSTOXX}_{t_{j}}$ denotes the daily implied volatility for the $j=1, \ldots, \tau$ trading days of month $t$. VSTOXX index is based on option prices and it is constructed by STOXX limited. ${ }^{7}$

\subsection{Structural VAR Model}

Using a Structural VAR framework, we examine the effects of three oil prices shocks on stock market volatility (VOL). Namely, the oil price shocks are the supply-side shocks, aggregate demand shocks and oil specific demand shocks, as these are identified from changes in world oil production (PROD), global economic activity (GEA) and changes in oil prices (OP), respectively. VOL is the generic name of the volatility series. For each SVAR model the volatility variable will be named after the method of estimation (i.e. conditional, realized or implied volatility) and the name of the index (either aggregate or industrial). ${ }^{8}$

The structural representation of the VAR model of order $p$ takes the following general form:

$$
\mathbf{A}_{0} \mathbf{y}_{t}=\mathbf{c}_{0}+\sum_{i=1}^{p} \mathbf{A}_{i} \mathbf{y}_{t-i}+\boldsymbol{\varepsilon}_{t}
$$

where, $\mathbf{y}_{t}$ is a $[4 \times 1]$ vector of endogenous variables, i.e. $\mathbf{y}_{t}=\left[P R O D_{t}, G E A_{t}, O P_{t}, V O L_{t}\right], \mathbf{A}_{0}$ represents the [4x4] contemporaneous

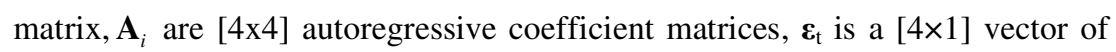
structural disturbances, assumed to have zero covariance and be serially uncorrelated. The covariance matrix of the structural disturbances takes the following form $E\left[\boldsymbol{\varepsilon}_{t} \boldsymbol{\varepsilon}_{t}^{\prime}\right]=\mathbf{D}=\left[\begin{array}{llll}\sigma_{1}^{2} & \sigma_{2}^{2} & \sigma_{3}^{2} & \sigma_{4}^{2}\end{array}\right] \times \mathbf{I}$. In order to get the reduce form of our structural model (1) we multiply both sides with $\mathbf{A}_{0}^{-1}$, such as that:

$$
\mathbf{y}_{t}=\mathbf{a}_{0}+\sum_{i=1}^{p} \mathbf{B}_{i} \mathbf{y}_{t-i}+\mathbf{e}_{t}
$$

where, $\mathbf{a}_{0}=\mathbf{A}_{0}^{-1} \mathbf{c}_{0}, \mathbf{B}_{i}=\mathbf{A}_{0}^{-1} \mathbf{A}_{i}$, and $\mathbf{e}_{t}=\mathbf{A}_{0}^{-1} \boldsymbol{\varepsilon}_{t}$, i.e. $\boldsymbol{\varepsilon}_{t}=\mathbf{A}_{0} \mathbf{e}_{t}$. The reduced form errors $\mathbf{e}_{t}$ are linear combinations of the structural errors $\boldsymbol{\varepsilon}_{t}$, with a covariance matrix of the form $E\left[\mathbf{e}_{t} \mathbf{e}_{t}^{\prime}\right]=\mathbf{A}_{0}^{-1} \mathbf{D A}_{0}^{-1^{\prime}}$.

The structural disturbances can be derived by imposing suitable restrictions on $\mathbf{A}_{0}$. The following short-run restrictions are imposed in the model:

$$
\left[\begin{array}{c}
\varepsilon_{1, t}^{S S} \\
\varepsilon_{2, t}^{A D S} \\
\varepsilon_{3, t}^{O S S} \\
\varepsilon_{4, t}^{V S}
\end{array}\right]=\left[\begin{array}{cccc}
a_{11} & 0 & 0 & 0 \\
a_{21} & a_{22} & 0 & 0 \\
a_{31} & a_{32} & a_{33} & 0 \\
a_{41} & a_{42} & a_{43} & a_{44}
\end{array}\right] \times\left[\begin{array}{c}
e_{1, t}^{P R O D} \\
e_{2, t}^{G E A} \\
e_{3, t}^{O P} \\
e_{4, t}^{V O L}
\end{array}\right]
$$

where SS=supply-side shocks, ADS=aggregate demand shock, OSS=oil specific demand shock and VS=volatility shock.

The restrictions in the model are explained as follows. The oil production is not responding contemporaneously to an increase/decrease of oil

\footnotetext{
${ }^{7}$ The interested reader can find all the necessary information about volatility index in the following link: http://www.stoxx.com/indices/index_information.html?symbol=V2TX.

${ }^{8}$ For example, the realized volatility of the industrial sector will be named RV_INDUSTRIAL.
} 
demand, caused by higher/lower economic activity, due to the adjustment costs of oil production. However, oil supply disruption (supply-side shock) can influence the global economic activity, the price of oil and the stock market volatility, within the same month. The global economic activity is not contemporaneously influenced by oil prices due to the time that is required for the world economy to react. On the contrary, an aggregate demand shock will have an immediate impact on oil prices and stock market volatility, considering the reaction time of the commodities and financial markets. Turning to the oil price innovation, any increase in the price can be driven by supply-side event, aggregate demand-side events, as well as, oil specific demand events. Thus, oil production shocks, as well as, aggregate demand shocks can contemporaneously trigger responses from the oil prices. In highly liquid markets as the European market, the stock market volatility reacts contemporaneously to all aforementioned oil price shocks.

To proceed to the estimation of the reduced form of model (1), it is first necessary to establish the stationarity of the variables. The ADF and PP unit root tests suggest that all variables are $\mathrm{I}(0)$. The lag length of the VAR model was identified using the Akaike Information Criterion (AIC). The AIC selects a VAR model with four lags. ${ }^{9}$

\section{DATA DESCRIPTION}

In order to estimate the volatility figures we use daily data from January 1999 to December 2010 on aggregate European stock market indices. In particular, the stock market index used is Eurostoxx 50, which is Europe's leading blue chips stock market index and the data have been extracted from Datastream $^{\circledR}$. In addition, we consider the following industrial sectors indices, which have been constructed by Dow Jones: Financials, Oil\&Gas, Retail, Consumption Goods, Health, Industrial, Basic Materials, Technology, Telecommunications and Utilities. The industrial sector indices data have been extracted from Datastream ${ }^{\circledR}$. For consistency purposes we have also considered the pan-European stock market index constructed by Dow Jones. As mentioned in section 2.1 once the daily volatility figures have been estimated, we then convert them into monthly figures.

Furthermore, we use monthly data for the same time period for oil production, oil prices and global economic activity. Brent crude oil is chosen, as a proxy of world oil price, due to the fact that this type of oil represents the $60 \%$ of the world oil daily consumption (Maghyereh, 2004). We use oil production data, as a proxy for oil supply. Both Brent crude oil price and oil production data have been extracted from the Energy Information Administration. Finally, we adopt Kilian's (2009) measurement of the global economic activity based on dry cargo freight rates. ${ }^{10}$ Prices are expressed in dollar terms and are transformed in log-returns.

Figure 1 presents the volatility measures for the Eurostoxx 50 index (realized volatility-RV_STOXX50, conditional volatility-CV_STOXX50 and implied volatility-VSTOXX), the growth rate of the world oil production, the global economic activity and the oil price returns. ${ }^{11}$

\section{[FIGURE 1 HERE]}

\footnotetext{
${ }^{9}$ Results are available upon request. The SVAR models do not suffer from autocorrelation and no inverse roots of the characteristic polynomial lie outside the unit circle. Thus, we conclude that the SVAR models satisfy the stability condition.

${ }^{10}$ The data can be found in Lutz Kilian personal website (http://www-personal.umich.edu/ lkilian/)

${ }^{11}$ The volatility graphs for the pan-European stock market index and the industrial sectors indices are available upon request.
} 
It is immediately apparent that volatility (in all three expressions) reaches a peak near the end of 2008 and again in May 2010. These periods coincide with the world financial crisis and the Greek debt crisis, respectively. Similar patterns are observed in the volatility measures of the pan-European stock market index by Dow Jones and of all industrial sectors' indices (not presented visually here, though). During 2008, we also observe a trough in the global economic activity and extreme negative returns for the oil prices. This period has been also characterized by demand driven oil price shocks. These preliminary findings may suggest that stock market volatility responds heavily to demand driven oil price shocks. Nevertheless, the impulse responses from the SVAR model will provide us with a clearer picture.

Furthermore, Table 1 presents some descriptive statistics for the volatility measures of the Eurostoxx 50 index and the three oil variables. The mean values of the realized volatility and conditional volatility are very close, whereas the VSTOXX mean value is higher. In addition, all volatility measures exhibit a significant variation over time which is evident by the minimum, maximum and standard deviation statistics. Naturally, the volatility measures are positively skewed and leptokurtic.

\section{[TABLE 1 HERE]}

As far as the oil variables are concerned, the global economic activity is the most volatile one, followed by the oil price returns. Both variables are negatively skewed, whereas the oil production growth rates are positively skewed. The skewness measures suggest that there are more negative oil logreturns and changes in the global economic activity, whereas the oil production exhibits more positive returns.

\section{ESTIMATION RESULTS}

The purpose of the SVAR model is to examine the dynamic adjustments of each of the variables to exogenous stochastic structural shocks (see, inter alia, Bjørnland and Leitemo, 2009; Kilian and Park, 2009). Thus, next we present the SVAR model findings for the volatility indices of the Eurostoxx50 and the industrial sectors in terms of the impulse response functions (IRF) and the variance decomposition. ${ }^{12}$

Section 4.1 describes the estimation results based on current-looking measures of stock market volatility (conditional and realized volatilities). The results on the aggregate stock market and industrial sector indices are summarized in Sections 4.1.1 and 4.1.2, respectively. Section 4.2 describes the estimation results based on the forward-looking measure of stock market volatility (implied volatility). Section 4.3 summarizes the robustness checks.

\subsection{Current-looking Volatility Measures}

\subsubsection{Aggregate European Stock Market Indices}

The impulse responses (Figure 2) depict that the reaction of the volatility measures of the Eurostoxx 50 index on the three oil shocks differ quite substantially.

\section{[FIGURE 2 HERE]}

\footnotetext{
${ }^{12}$ The SVAR results for the pan-European stock market index constructed by Dow Jones ${ }^{\circledR}$ are qualitatively similar and thus they are not presented here. They are available upon request.
} 
Changes in world oil production do not exercise any significant impact on stock market volatility. The argument that the OPEC's decisions on oil production levels do not impact stock markets nowadays, finds support here. Thus, this finding does not come with a surprise. Furthermore, the fact that stock market volatility is not reacting to supply-side oil prices shocks complements the evidence provided by Basher et al. (2012), Filis et al. (2011) and Kilian and Park (2009), who argue that changes in oil production do not affect stock price returns. Similar observation can be made for the oil specific demand shock, as its effect is not significant on any volatility measure. A plausible explanation of this result lies in the nature of firms' responses to oil price changes. We argue that firms, nowadays, engage in effective hedging strategies which reduce the effects of adverse oil price movements (Arouri, 2011), mainly caused by idiosyncratic oil price shocks (or oil specific demand shocks). On the contrary, increases in world's aggregate demand, which implies increased economic activity, tend to reduce stock market volatility, as expected. A positive aggregate demand shock can be regarded as good news to the stock market. In the event of a positive aggregate demand shock, uncertainty about future cash flows decreases, driving down stock market volatility. One can also argue that positive news about global economic activity is associated with a more stable business environment, which, in turn, reduces the uncertainty in the market. From an opposite angle, Bloom (2009) has shown that negative news about the global economic activity, such as those during the Asian crisis in 1997 and the credit crunch in 2008 , tend to increase stock market volatility. In general, stock markets tend to respond favorably when the world economic developments are positive. The preliminary findings had already provided with an initial idea about the inverse link between aggregate demand oil price shocks and stock market volatility. Overall, the response is significant for about 6 months and dynamic convergence is achieved after 12 months after the shock, for both volatility measures.

In regard with the variance decomposition (Table 2), we observe that the effects of the supply-side and oil specific demand shocks are very small and insignificant, suggesting that these shocks do not exercise an impact on stock market volatility. Furthermore, the effects of the aggregate demand shocks are small and significant in the short-run; however their explanatory power exhibits an increasing pattern (remaining significant) as the forecasting window increases. This is suggestive of the fact that the aggregate demand shocks have a very important role in the European stock market volatility.

\section{[TABLE 2 HERE]}

In more detail, about $9 \%-18 \%$ (depending on the volatility measure) of the variation in the volatility of the Eurostoxx50 index is associated with the oil price shocks, during the first few months. In a period of 24 months a total of $24 \%-38 \%$ of the variability of the volatility is explained by the oil price shocks. The main contributor to this variability is the aggregate demand oil price shock in both volatility measures. Linking these findings with the evidence on stock market returns (see, for example, Kilian and Park, 2009; Hamilton, 2009a,b) it is suggested that supply-side shocks do not seem to influence any of the stock markets characteristics (i.e. returns and volatilities), whereas demand-side shocks - and in particular the aggregate demand oil price shocks - do.

Overall, the results suggest that increases in oil prices due to increased global economic activity (aggregate demand shock) reduce stock market volatility, as positive development is the global economic activity is regarded as positive information by the stock markets. 


\subsubsection{European Industrial Sectors}

Having analyzed the effects of the three oil shocks on the aggregate stock market volatility, we proceed to the analysis of these effects on the industrial sectors. $^{13}$

The impulse responses (Figure 3) suggest that the reaction of the volatility measures of the industrial sectors on the three oil shocks is similar to these of the Eurostoxx50 volatility measures. More specifically, the aggregate demand shock is exercising a significant negative effect on industrial sectors' volatility (the same result holds for both the realized volatility and the conditional volatility). The supply-side oil price shocks and the oil specific demand shocks do not seem to influence any of the sectors' realized or conditional volatilities. ${ }^{14}$

\section{[FIGURE 3 HERE]}

The only exemption is the Oil\&Gas sector. Both the realized and conditional volatility of the Oil\&Gas sector respond negatively to the two demand-side shocks (i.e. aggregate demand shock and oil specific demand shock). This finding is expected since any increase in oil price is received as positive news for the companies listed in the Oil\&Gas sector. The effects remain significant for about 3-4 months and they are fully absorbed after 8 to 10 months. It could be argued that supply-side shocks should also benefit the Oil\&Gas sector; nevertheless, we cannot find such evidence in this study.

Overall, the findings suggest that disruptions or increases in world oil production do not provide any information for the volatility of any sector, even the Oil\&Gas one. The opposite holds for the aggregate demand oil price shocks.

The variance decomposition analysis (Table 3) illustrates that the three oil price shocks exercise the highest influence on the RV_OIL\&GAS and CV_OIL\&GAS (about 53\%), as expected, and it is followed by the RV_CONSUMPTION and CV_CONSUMPTION (about 40\%). The latter is expected to be influenced heavily from the oil price shocks considering that Europe is mainly an oil importing region. Regarding the remaining industrial indices, the three oil price shocks explain about $10 \%-20 \%$ of the variability of their volatility. The lowest influenced is observed in the realized and conditional volatility of the Financials sector (about 10\%), suggesting that the Financials sector's volatility is mainly influenced by other variables, rather than the oil price shocks. The main contributor of this influence, in all cases, is the aggregate demand shock, a similar finding with the aggregate European stock market volatility. ${ }^{15}$

[TABLE 3 HERE]

\subsection{Forward-looking Volatility Measure}

The impulse responses (Figure 4) of the Eurostoxx 50 implied volatility (VSTOXX) measure is essential the same with those produced by the conditional and realized volatilities.

\section{[FIGURE 4 HERE]}

\footnotetext{
${ }^{13}$ The descriptive statistics and figures of the industrial sectors' volatility measures are available upon request.

${ }^{14}$ Figures for the impulse responses of the industrial sectors' realized volatilities are available upon request.

${ }^{15}$ The variance decomposition of the industrial sectors' realized volatilities is available upon request.
} 
Again, both supply-side oil price shocks and oil specific demand shocks do not exercise any significant impact on implied volatility, whereas positive aggregate demand oil price shocks trigger a negative response.

In terms of the variance decomposition (Table 4), we observe that the explanatory power of the three oil price shocks on implied volatility exhibits a peak in the medium-term and starts to decline thereafter until it reaches a stable level after 24 months.

\section{[TABLE 4 HERE]}

More specifically, in the first month about $9 \%$ of the variation in the implied volatility is associated with the oil price shocks, whereas in a period of 6-12 months this figure increases to an average of $22 \%$. The main contributor to this variability is the aggregate demand oil price shock, as also suggested by the conditional and realized volatilities.

Comparing the results among the three volatility measures, we observe that these measures provide qualitatively and quantitatively similar information. Hence, the implied volatility index (a forward-looking volatility measure) does not provide additional information compared to the conditional and realized volatility measures, which estimate the market volatility at the current time. This is a very interesting finding considering that several aforementioned studies have concluded that implied volatility indices provide superior information (see Xekalaki and Degiannakis, 2010; Becker et al., 2007; Andersen et al., 2005a; Andersen et al., 2001 and Bollerslev et al., 1992). Despite the fact that this result may come as a surprise, it does not remain without a possible explanation. It is worth noting that this result does not contradict the forward-looking feature of the implied volatility measure. The impulse responses of the current-looking volatility measures depict that the effects of the aggregate demand oil price shocks do not fade out immediately, but rather they require about 12 months to be fully absorbed. This means that the impact remains for the future months and this is what it is captured by the implied volatility response to the aggregate demand oil price shocks. The uncharacteristically prolonged response of the implied volatility is also artifact of its long memory, as documented in Section 4.3.

\subsection{Robustness Checks}

In order to test for the robustness of our results a battery of alternative approaches has been employed. ${ }^{16}$ More specifically, we estimate two volatility models (one with short memory and one with long memory) and we examine whether the aggregate demand oil price shock series has explanatory power on stock market volatility. The choice of the aggregate demand oil price shock series is justified by the fact that it was the only oil price shock that showed to have a significant effect on stock market volatility, based on the impulse response functions. Because stock market volatility is found invariant to the supply-side shock and the oil specific demand shock, we deliberately discard these two shocks from our robustness exercise.

First, we construct the aggregate demand oil price shock series (ADS). In order to achieve that we proceed to a historical decomposition of the effects of all three oil price shocks on the oil price returns.

The historical decomposition procedure can be summarized in three steps. In the first step, we estimate a structural VAR on changes in oil production, global economic activity and oil price returns, identifying the

\footnotetext{
${ }^{16}$ The detailed results from the short-and long memory volatility models are available from the authors upon request.
} 
supply-side shock, the aggregate demand shock and the oil specific demand shock, respectively. In a second step, we use the estimated VAR model to forecast the endogenous variables. In a third step, we decompose the forecast errors into the cumulative contributions of the structural oil-price shocks (see Burbidge and Harrison, 1985).

We then use the cumulative effect of the aggregate demand shocks $(A D S)$ on oil price log-returns as an explanatory variable in a short-and long memory volatility models. The estimation results suggest that $A D S$ exercises a negative and significant effect on stock market volatility. The results are qualitatively similar for the three volatility measures and for both the aggregate stock market and industrial sector indices. In particular, a positive aggregate demand shock causes a reduction in the stock market volatility, which confirms the findings of the SVAR model. The results are, thus, of particular importance as they could facilitate traders, investors, researchers or policy makers, should they need to forecast stock market volatility, price derivatives, manage risk and formulate regulation.

\section{CONCLUDING REMARKS}

The study examines the effects of three oil prices shocks (i.e., supplyside shock, aggregate demand shock and oil specific demand shock) on stock market volatility using a Structural VAR framework. We consider two volatility measures, namely the conditional volatility and the realized volatility, which measure the current stock market volatility. We also examine the effects of oil price shocks on implied volatility, as well, which is a forward-looking volatility measure.

We conclude that supply-side and oil specific demand shocks do not affect volatility, whereas, aggregate demand shocks influence volatility at a significant level. This finding holds for both the current-looking volatility and the implied volatility measures of aggregate stock market and industrial sector indices. Furthermore, the two volatility models (short- and long-memory models) verify the SVAR results, suggesting that the effect of the aggregate demand oil price shocks on volatility is negative and significant for all indices and all measures. The findings of the study are essential in pricing financial derivatives, selecting portfolios, measuring and managing investment risk. Investors, risk managers, even policy makers of Central Banks and Capital Market Commissions will find the outcomes of the study useful in handling market's uncertainty in relation with the state of the oil price shocks. For example, supervisors of financial institutions must hold capital based on its internal model's estimates of Value-at-Risk. The Value-at-Risk internal model can take into consideration the interrelation between oil price shocks and stock market volatility. Basel Committee, in order to strengthen bank capital requirements and introduce enhanced regulatory requirements on bank liquidity, may take advantage of the ability to model the relationship between aggregate demand oil price shocks and volatility of European stock markets.

It is essential that further studies will distinguish such effects for oilimporting and oil-exporting countries and conditional correlation models can be used to identify the aforementioned relationships in a time-varying environment. Finally, following Andersen et al. (2005b), an interesting question underpinning this research is whether and, if so, how the betas of European stock market sectors respond to different oil price shocks. 


\section{ACKNOWLEDGMENTS}

We would like to thank one editor Prof. Lester Hunt and the two anonymous referees for their constructive comments and suggestions which helped us to improve the scope and clarity of the paper. We thank the participants of the $10^{\text {th }}$ INFINITI Conference on International Finance and the $2^{\text {nd }}$ International Conference of the Financial Engineering and Banking Society for their comments and Prof. Robin Lumsdaine for her valuable suggestions. Dr. Stavros Degiannakis acknowledges the support from the European Community's Seventh Framework Programme (FP7-PEOPLE-IEF) funded under grant agreement no. PIEF-GA-2009-237022. The authors are solely responsible for any remaining errors and deficiencies.

\section{REFERENCES}

Andersen, T.G. and T. Bollerslev (1998). “Answering the Skeptics: Yes, Standard Volatility Models Do Provide Accurate Forecasts." International Economic Review 39(4): 885-905.

Andersen, T.G., T. Bollerslev, F.X. Diebold, and H. Ebens (2001). "The Distribution of Stock Return Volatility.” Journal of Financial Economics 61(1): 43-76.

Andersen, T.G., T. Bollerslev, F.X. Diebold, and P. Labys (2003). "Modeling and Forecasting Realized Volatility." Econometrica 71(2): 529-626.

Andersen, T.G., T. Bollerslev, and N. Meddahi (2005a). "Correcting the Errors: Volatility Forecast Evaluation Using High-frequency Data and Realized Volatilities." Econometrica 73(1): 279296.

Andersen, T.G., T. Bollerslev, F.X. Diebold, and J. Wu (2005b). "A Framework for Exploring the Macroeconomic Determinants of Systematic Risk." American Economic Review, Papers Proceedings of the One Hundred Seventeenth Annual Meeting of the American Economic Association 95(2): 398-404.

Apergis, N. and S.M. Miller (2009). "Do Structural Oil-Market Shocks Affect Stock Prices?" Energy Economics 31(4): 569-575.

Arouri, M.E.H. (2011). "Does Crude Oil Move Stock Markets in Europe? A Sector Investigation." Economic Modelling 28(4): 1716-1725.

Arouri, M.E.H. and D.K. Nguyen (2010). "Oil Prices, Stock Markets and Portfolio Investment: Evidence from Sector Analysis in Europe over the Last Decade.” Energy Policy 38(8): 45284539.

Arouri, M.E.H., J. Jouini and D.K. Nguyen (2011). "Volatility Spillovers between Oil Prices and Stock Sector Returns: Implications for Portfolio Management." Journal of International Money and Finance 30(7): 1387-1405.

Arouri, M.E.H., J. Jouini and D.K. Nguyen (2012). "On the Impacts of Oil Price Fluctuations on European Equity Markets: Volatility Spillover and Hedging Effectiveness.” Energy Economics 34(2): 611-617.

Arouri, M.E.H. and C. Rault (2012). "Oil Prices and Stock Markets in GCC Countries: Empirical Evidence from Panel Analysis.” International Journal of Finance and Economics 17(3): 242253.

Barndorff-Nielsen, O.E. and N. Shephard (2002). "Econometric Analysis of Realised Volatility and its Use in Estimating Stochastic Volatility Models." Journal of the Royal Statistical Society: Series B 64(2): 253-280.

Barsky, R. and L. Kilian (2004). "Oil and the Macroeconomy Since the 1970s." Journal of Economic Perspectives 18(4): 115-134.

Basher, S.A., A.A. Haug, and P. Sadorsky (2012). "Oil Prices, Exchange Rates and Emerging Stock Markets.” Energy Economics 34(1): 227-240.

Baum, C.F., M. Caglaynan, and O. Talavera (2010). "On the Sensitivity of Firms' Investment to Cash Flow and Uncertainty." Oxford Economic Papers 62(2): 286-306.

Baumeister, C. and G. Peersman (2012). "Time-varying Effects of Oil Supply Shocks on the US Economy." Bank of Canada Working Paper Series, WP2012-02.

Becker, R., A.E. Clements, and S.I. White (2007). "Does Implied Volatility Provide Any Information Beyond That Captured in Model-based Volatility Forecasts?" Journal of Banking and Finance 31(8): 2535-2549.

Bernanke, B.S. (1983). “Irreversibility, Uncertainty, and Cyclical Investment." Quarterly Journal of Economics 98(1): 85-106.

Bjørnland, H.C. (2009). "Oil Price Shocks and Stock Market Booms in an Oil Exporting Country." Scottish Journal of Political Economy 56(2): 232-254.

Bjørnland, H.C. and K. Leitemo (2009). "Identifying the Interdependence Between US Monetary Policy and the Stock Market.” Journal of Monetary Economics 56(2): 275-282.

Blair, B.J., S.-H. Poon, and S.J. Taylor (2001). "Forecasting S\&P100 Volatility: The Incremental 
Information Content of Implied Volatilities and High-frequency Index Returns." Journal of Econometrics 105(1): 5-26.

Bloom, N. (2009). "The Impact of Uncertainty Shocks.” Econometrica 77(3): 623-685.

Bollerslev, T., R.Y. Chou, and K.F. Kroner (1992). "ARCH Modeling in Finance: A Review of the Theory and Empirical Evidence.” Journal of Econometrics 52(1-2): 5-59.

Burbidge, J. and A. Harrison (1985). "A Historical Decomposition of the Great Depression to Determine the Role of Money." Journal of Monetary Economics 16(1): 45-54.

Chen, S.-S. (2009). "Do Higher Oil Prices Push the Stock Market Into Bear Territory?" Energy Economics 32(2): 490-495.

Chiou, J.-S. and Y.-H. Lee (2009). "Jump Dynamics and Volatility: Oil and the Stock Markets." Energy 34(6): 788-796.

Christensen, B.J. and N.R. Prabhala (1998). "The Relation Between Implied and Realised Volatility." Journal of Financial Economics 50(2): 125-150.

Corrado, C. and C. Truong (2007). "Forecasting Stock Index Volatility: Comparing Implied Volatility and the Intraday High-Low Price Range.” Journal of Financial Research 30(2): 201215.

Cong, R.-G., Y.-M. Wei, J.-L. Jiao, and Y. Fan (2008). "Relationships Between Oil Price Shocks and Stock Market: An Empirical Analysis From China.” Energy Policy 36(9): 3544-3553.

Day, T.E. and C.M. Lewis (1992). "Stock Market Volatility and the Information Content of Stock Index Options.” Journal of Econometrics 52(1-2): 267-287.

Ding, Z., C.W.J. Granger, and R.F. Engle (1993). "A Long Memory Property of Stock Market Returns and a New Model.” Journal of Empirical Finance 1(1): 83-106.

Driesprong, G., B. Jacobsen, and B. Maat (2008). "Striking Oil: Another Puzzle?" Journal of Financial Economics 89(2): 307-327.

Ebens, H. (1999). "Realized Stock Volatility". Johns Hopkins University, Department of Economics, Working Paper, 420.

Elder, J. and A. Serletis (2011). "Oil Price Uncertainty". Journal of Money, Credit and Banking 42(6): 1137-1159.

Engle, R.F. (2002). "New Frontiers for ARCH Models". Journal of Applied Econometrics 17(5): $425-446$.

Filis, G. (2010). "Macro Economy, Stock Market and Oil Prices: Do Meaningful Relationships Exist Among Their Cyclical Fluctuations?" Energy Economics 32(4): 877-886.

Filis, G., S. Degiannakis, and C. Floros (2011). "Dynamic Correlation Between Stock Market and Oil Prices: The Case of Oil-importing and Oil-exporting Countries." International Review of Financial Analysis 20(3): 152-164.

Fleming, J. (1998). "The Quality of Market Volatility Forecasts Iimplied by S\&P 100 Index Option Prices." Journal of Empirical Finance 5(4): 317-345.

Gjerde, Ø. and F. Sættem (1999). "Causal Relations Among Stock Returns and Macroeconomic Variables in a Small, Open Economy." Journal of International Financial Markets, Institutions and Money 9(1): 61-74.

Hamilton, J.D. (2009a). “Understanding Crude Oil Prices.” Energy Journal, 30(2), 179-206.

Hamilton, J.D. (2009b). "Causes and Consequences of the Oil Shock of 2007-08." Brookings Papers on Economic Activity Spring 2009: 215-261.

Haung, R.D., R.W. Masulis, and H.R. Stoll (1996). "Energy Shocks and Financial Markets.” Journal of Futures Markets 16(1): 1-27.

Henriques, I. and P. Sadorsky (2011). "The Effect of Oil Price Volatility on Strategic Investment." Energy Economics 33(1): 79-87.

Hentschel, L. (1995). "All in the Family: Nesting Symmetric and Asymmetric GARCH Models." Journal of Financial Economics 39(1): 71-104.

Jammazi, R. and C. Aloui (2010). "Wavelet Decomposition and Regime Shifts: Assessing the Effects of Crude Oil Shocks on Stock Market Returns.” Energy Policy 38(3): 1415-1435.

Jones, M.C. and G. Kaul (1996). "Oil and the Stock Markets.” Journal of Finance 51(2): 463-491.

Kilian, L. (2008). "Exogenous Oil Supply Shocks: How Big Are They and How Much Do They Matter for the U.S. Economy?" Review of Economics and Statistics 90(2): 216-240.

Kilian, L. (2009). "Not All Oil Price Shocks Are Alike: Disentangling Demand and Supply Shocks in the Crude Oil Market." American Economic Review 99(3): 1053-1069.

Kilian, L. and L.T. Lewis (2011). "Does the Fed Respond To Oil Price Shocks?" The Economic Journal 121(555): 1047-1072.

Kilian, L. and C. Park (2009). "The Impact of Oil Price Shocks on the U.S. Stock Market." International Economic Review 50(4): 1267-1287.

Koopman, S.J., B. Jungbacker, and E. Hol (2005). "Forecasting Daily Variability of the S\&P100 Stock Index Using Historical, Realised and Implied Volatility Measurements." Journal of Empirical Finance 12(3): 445-475.

Laurent, S. (2004). “Analytical Derivatives of the APARCH Model.” Computational Economics 24: 51-57.

Lescaroux, F. and V. Mignon (2008). "On the Influence of Oil Prices on Economic Activity and Other Macroeconomic and Financial Variables.” OPEC Energy Review 32(4): 343-380.

Lippi, F. and A. Nobili (2012). "Oil and the Macroeconomy: A Quantitative Structural Analysis." Journal of the European Economic Association 10(5): 1059-1083. 
Maghyereh, A. (2004). "Oil Price Shocks and Emerging Stock Markets. A Generalized VAR Approach." International Journal of Applied Econometrics and Quantitative Studies 1(2): $27-$ 40.

Malik, F. and B.T. Ewing (2009). "Volatility Transmission Between Oil Prices and Equity Sector Returns." International Review of Financial Analysis 18(3): 95-100.

Merton, R.C. (1980). "On Estimating the Expected Return on the Market: An Explanatory Investigation.” Journal of Financial Economics 8: 323-361.

Miller, J.I. and R.A. Ratti (2009). "Crude Oil and Stock Markets: Stability, Instability, and Bubbles." Energy Economics 31(4): 559-568.

Park, J. and R.A. Ratti (2008). "Oil Prices and Stock Markets in the U.S. and 13 European Countries." Energy Economics 30(5): 2587-2608.

Pindyck, R.S. (1991). "Irreversibility, Uncertainty, and Investment." Journal of Economic Literature 29(3): 1110-1148.

Rahman, S. and A. Serletis (2011). "The Asymmetric Effects of Oil Price Shocks.” Macroeconomic Dynamics 15(S3): 437-471.

Ratti, R.A., Y. Seol and K.H. Yoon (2011). "Relative Energy Price and Investment by European Firms." Energy Economics 33(5): 721-731.

Sadorsky, P. (1999). “Oil Price Shocks and Stock Market Activity.” Energy Economics 21(5): 449469.

Sadorsky, P. (2011). "Correlations and Volatility Spillovers Between Oil Prices and the Stock Prices of Clean Energy and Technology Companies.” Energy Economics 34(1): 248-255.

Scholtens, B. and C. Yurtsever (2012). "Oil Price Shocks and European Industries." Energy Economics 34(4): 1187-1195.

Vo, M. (2011). "Oil and Stock Market Volatility: A Multivariate Stochastic Volatility Perspective." Energy Economics 33(5): 956-965.

Xekalaki, E. and S. Degiannakis (2010). ARCH Models for Financial Applications. New York: Wiley. 
Figures

Figure 1: Volatility Measures of the Eurostoxx 50 Index, Oil Production Growth Rate, Global Economic Activity and Oil Price Returns

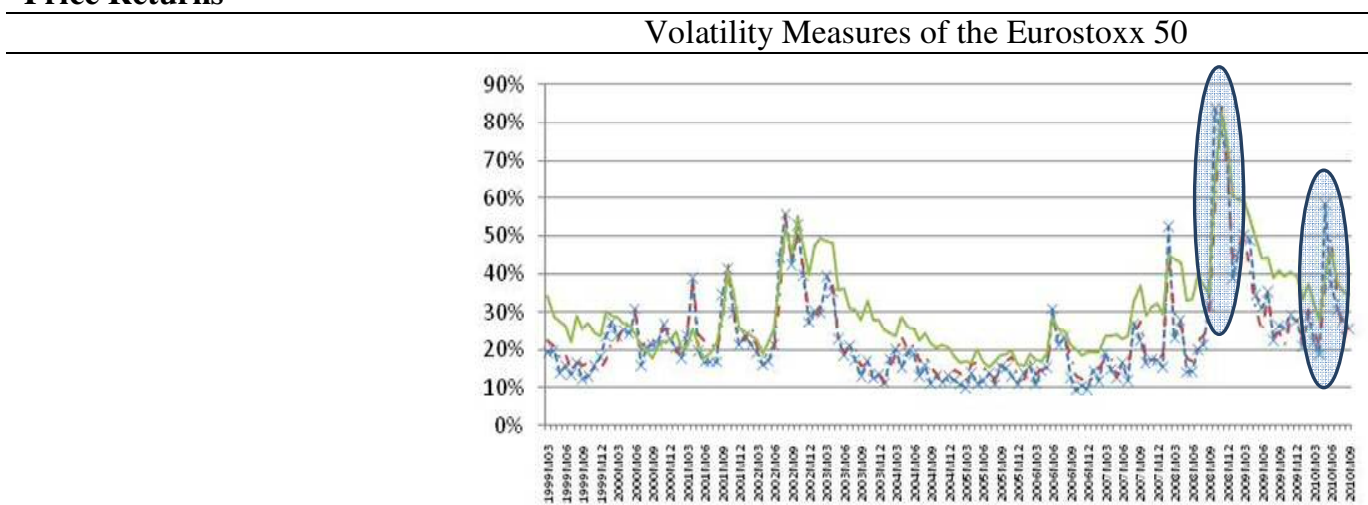

-----RV_STOXX50 -.... CV_STOXX50 -VSTOXX

Oil Production Growth Rate (PROD)

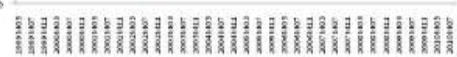

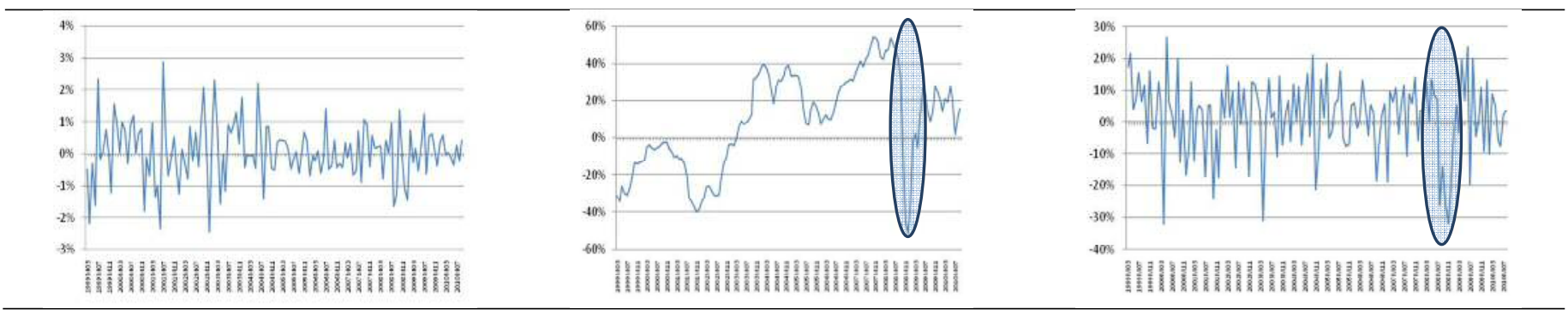

Global Economic Activity (GEA)

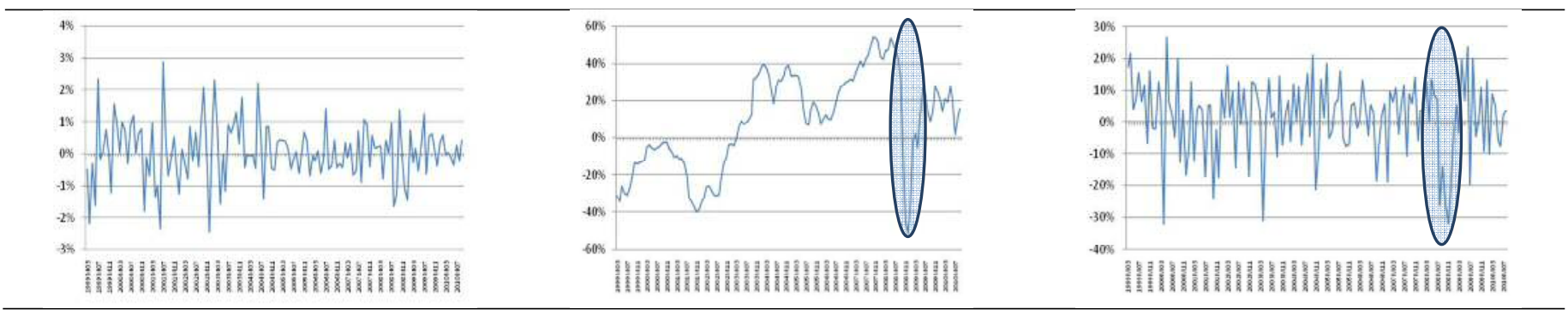

Oil Price Returns (OP) 


\section{Figure 2: Impulse Responses of Current-looking Volatility Measures}
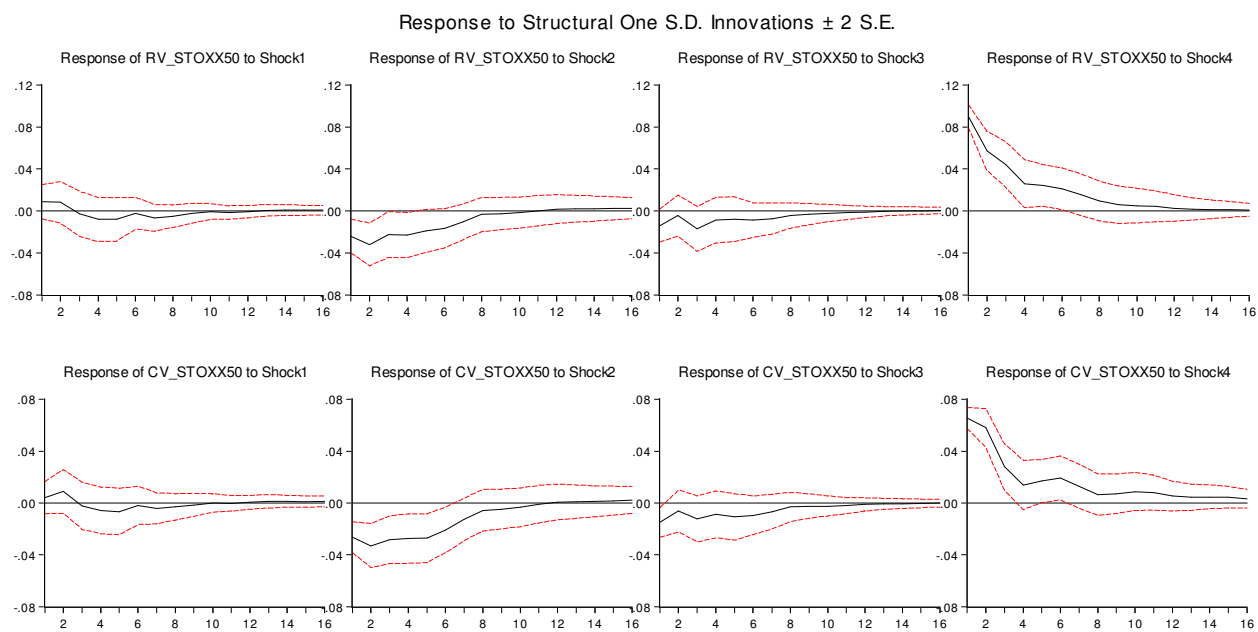

Note: Shock 1 refers to the supply-side shock (PROD), Shock 2 refers to the aggregate demand shock (GEA), Shock 3 refers to the oil specific demand shock (OP) and Shock 4 refers to the volatility shock (VOL). 


\section{Figure 3: Impulse Responses of the Industrial Sectors' Conditional Volatility Measures}
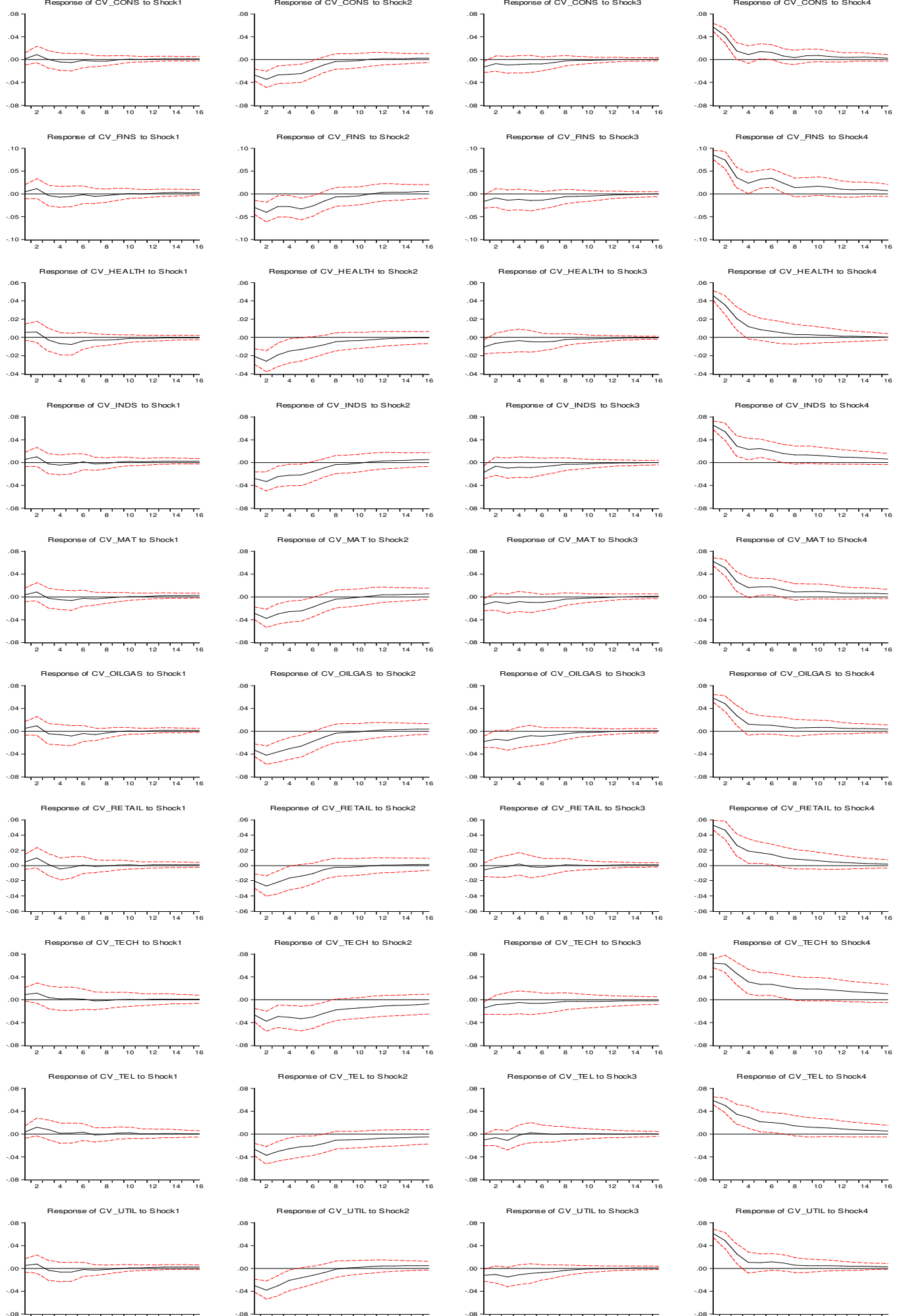

Note: Shock 1 refers to the supply-side shock (PROD), Shock 2 refers to the agregate demand shock (GEA), Shock 3 refers to the oil specific demand shock (OP) and Shock 4 refers to the volatility shock (VOL). The order of the industrial indices is as follows: Consumer Goods, Financials, Health, Industrials, Basic Material, Oil\&Gas, Retail, Technology, Telecommunications, and Utilities. 
Figure 4: Impulse Responses of the Forward-looking Volatility Measure

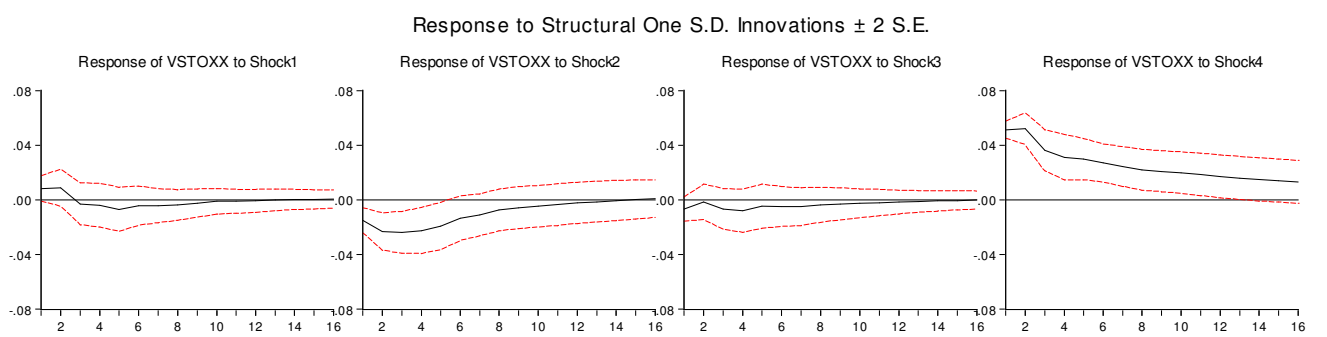

Note: Shock 1 refers to the supply-side shock (PROD), Shock 2 refers to the aggregate demand shock (GEA), Shock 3 refers to the oil specific demand shock (OP) and Shock 4 refers to the volatility shock (VOL). 
Tables

\begin{tabular}{|c|c|c|c|c|c|c|}
\hline & RV_STOXX50 & CV_STOXX50 & VSTOXX & PROD & GEA & OP \\
\hline Mean & $23.41 \%$ & $23.94 \%$ & $30.48 \%$ & $0.06 \%$ & $8.89 \%$ & $1.49 \%$ \\
\hline Max. & $83.55 \%$ & $85.70 \%$ & $82.72 \%$ & $2.89 \%$ & $54.30 \%$ & $26.75 \%$ \\
\hline Min. & $9.38 \%$ & $10.61 \%$ & $15.45 \%$ & $-2.44 \%$ & $-51.30 \%$ & $-32.11 \%$ \\
\hline Std. D. & $13.20 \%$ & $11.57 \%$ & $12.38 \%$ & $0.91 \%$ & $26.19 \%$ & $11.98 \%$ \\
\hline Skew. & 2.038 & 2.170 & 1.448 & 0.045 & -0.259 & -0.643 \\
\hline Kurt. & 8.013 & 9.510 & 5.466 & 3.813 & 2.099 & 3.248 \\
\hline
\end{tabular}

\begin{tabular}{|c|c|c|c|c|c|}
\hline $\begin{array}{l}\text { Volatility } \\
\text { Measure }\end{array}$ & Period & PROD & GEA & OP & VOL \\
\hline \multirow[t]{8}{*}{ CV_STOXX50 } & 1 & $\begin{array}{r}0.318 \\
(1.347)\end{array}$ & $\begin{array}{r}13.389^{*} \\
(5.525)\end{array}$ & $\begin{array}{r}4.334 \\
(3.098)\end{array}$ & $\begin{array}{r}81.959^{*} \\
(6.169)\end{array}$ \\
\hline & 3 & $\begin{array}{r}0.873 \\
(2.256)\end{array}$ & $\begin{array}{r}22.524^{*} \\
(8.408)\end{array}$ & $\begin{array}{r}3.613 \\
(3.472)\end{array}$ & $\begin{array}{r}72.990 * \\
(8.771)\end{array}$ \\
\hline & 6 & $\begin{array}{r}1.238 \\
(3091)\end{array}$ & $\begin{array}{l}30.827 * \\
(10364)\end{array}$ & $\begin{array}{r}4.793 \\
(4901)\end{array}$ & $63.141^{*}$ \\
\hline & 12 & $\begin{array}{r}1.370 \\
(3.687)\end{array}$ & $\begin{array}{c}30.799 * \\
(10.699)\end{array}$ & $\begin{array}{r}5.035 \\
(5.616)\end{array}$ & $\begin{array}{c}62.796^{*} \\
(11.577)\end{array}$ \\
\hline & \multirow[t]{2}{*}{18} & 1.417 & $30.720^{*}$ & 5.004 & $62.859 *$ \\
\hline & & $(3.781)$ & (10.704) & $(5.657)$ & (11.698) \\
\hline & \multirow[t]{2}{*}{24} & 1.469 & $30.872 *$ & 4.988 & $62.671 *$ \\
\hline & & $(3.847)$ & $(10.725)$ & $(5.638)$ & (11.771) \\
\hline \multirow[t]{12}{*}{ RV_STOXX50 } & \multirow[t]{2}{*}{1} & 0.835 & $6.425^{*}$ & 2.197 & $90.542 *$ \\
\hline & & $(1.840)$ & $(4.035)$ & (2.489) & $(4.796)$ \\
\hline & \multirow[t]{2}{*}{3} & 0.924 & $13.082 *$ & 3.188 & $82.806^{*}$ \\
\hline & & $(2.265)$ & $(6.615)$ & $(3.403)$ & (7.596) \\
\hline & \multirow[t]{2}{*}{6} & 1.459 & $16.996^{*}$ & 3.773 & $77.771 *$ \\
\hline & & (3.02) & (8.613) & $(4.492)$ & (9.528) \\
\hline & \multirow[t]{2}{*}{12} & 1.801 & $17.057^{*}$ & 4.092 & $77.050 *$ \\
\hline & & $(3.551)$ & $(8.642)$ & $(5.015)$ & $(10.470)$ \\
\hline & \multirow[t]{2}{*}{18} & 1.816 & $17.175^{*}$ & 4.087 & $76.921 *$ \\
\hline & & $(3.606)$ & $(8.732)$ & $(5.021)$ & (10.659) \\
\hline & \multirow[t]{2}{*}{24} & 1.837 & $17.257 *$ & 4.088 & $76.818 *$ \\
\hline & & $(3.650)$ & $(8.672)$ & $(5.003)$ & (10.783) \\
\hline
\end{tabular}

\begin{tabular}{|c|c|c|c|c|c|}
\hline \multicolumn{6}{|c|}{$\begin{array}{l}\text { Table 3: Variance } \\
\text { Volatilities }\end{array}$} \\
\hline Industrial sector & Period & PROD & GEA & OP & VOL \\
\hline \multirow[t]{10}{*}{ CV_CONSUMER } & 1 & 0.041 & $18.096^{*}$ & 3.970 & $77.892 *$ \\
\hline & 3 & $\begin{array}{r}(1.031) \\
1.031\end{array}$ & $\begin{array}{r}(6.062) \\
32.404 *\end{array}$ & $\begin{array}{r}(3.047) \\
3.616\end{array}$ & $\begin{array}{r}(6.334) \\
62.947 *\end{array}$ \\
\hline & & $(2.495)$ & (8.632) & $(3.428)$ & (8.932) \\
\hline & 6 & 1.206 & $40.208^{*}$ & 4.617 & $53.967 *$ \\
\hline & & (2.794) & $(10.145)$ & $(4.621)$ & (10.142) \\
\hline & 12 & 1.310 & $39.858 *$ & 4.779 & $54.052 *$ \\
\hline & & (3.191) & (10.497) & $(5.144)$ & (10.758) \\
\hline & 18 & 1.450 & $39.705^{*}$ & 4.737 & $54.106^{*}$ \\
\hline & & (3.261) & (10.484) & $(5.102)$ & (10.774) \\
\hline & 24 & 1.561 & $39.838 *$ & 4.737 & $53.863^{*}$ \\
\hline
\end{tabular}




\begin{tabular}{|c|c|c|c|c|c|}
\hline \multirow{13}{*}{ CV_FINANCIALS } & & $(3.331)$ & (10.487) & $(5.079)$ & (10.754) \\
\hline & \multirow[t]{2}{*}{1} & 0.278 & $10.733^{*}$ & 3.151 & $85.836^{*}$ \\
\hline & & $(1.371)$ & (4.926) & $(2.865)$ & $\begin{array}{r}(5.658) \\
77.850^{*}\end{array}$ \\
\hline & \multirow[t]{2}{*}{3} & 0.951 & $18.170^{*}$ & 3.027 & $\begin{array}{r}77.850^{*} \\
(8132)\end{array}$ \\
\hline & & $(2.310)$ & $(7.572)$ & $(3.477)$ & $(8.132)$ \\
\hline & \multirow[t]{2}{*}{6} & 1.042 & $24.285^{*}$ & 4.622 & $70.049^{*}$ \\
\hline & & $(2.851)$ & $(9.679)$ & $(4.907)$ & (10.328) \\
\hline & \multirow[t]{2}{*}{12} & 1.120 & $23.586^{*}$ & 5.066 & $70.226 *$ \\
\hline & & (3.384) & (10.074) & $(5.708)$ & (11.171) \\
\hline & \multirow[t]{2}{*}{18} & 1.280 & $23.621^{*}$ & 4.969 & $70.127 *$ \\
\hline & & $(3.470)$ & $(9.950)$ & $(5.565)$ & (11.229) \\
\hline & \multirow[t]{2}{*}{24} & 1.451 & $24.070^{*}$ & 4.907 & $69.571 *$ \\
\hline & & (3.551) & (9.908) & (5.574) & (11.269) \\
\hline \multirow[t]{12}{*}{ CV_HEALTH } & \multirow[t]{2}{*}{1} & 1.223 & $16.777^{*}$ & 4.077 & $77.922 *$ \\
\hline & & $(2.075)$ & $(5.751)$ & $(2.848)$ & $(6.159)$ \\
\hline & \multirow[t]{2}{*}{3} & 1.375 & $27.397^{*}$ & 3.096 & $68.130 *$ \\
\hline & & (2.394) & $(8.471)$ & (3.292) & $(8.795)$ \\
\hline & \multirow[t]{2}{*}{6} & 3.047 & $31.297^{*}$ & 3.547 & $62.106 *$ \\
\hline & & (3.798) & $(9.882)$ & $(4.035)$ & $(10.242)$ \\
\hline & \multirow[t]{2}{*}{12} & 3.363 & $32.055^{*}$ & 3.933 & $60.648 *$ \\
\hline & & $(4.191)$ & (10.317) & $(4.678)$ & (10.974) \\
\hline & 18 & 3.372 & $32.055^{*}$ & 3.947 & $60.624 *$ \\
\hline & & $(4.265)$ & (10.174) & $(4.760)$ & (11.230) \\
\hline & 24 & 3.372 & $32.055^{*}$ & 3.947 & $60.624 *$ \\
\hline & & $(4.301)$ & $(10.581)$ & $(4.786)$ & (11.384) \\
\hline CV_INDUSTRIAL & 1 & 0.623 & $15.027 *$ & 5.334 & $79.015^{*}$ \\
\hline & & (1.604) & $(5.678)$ & $(3.416)$ & $(6.352)$ \\
\hline & 3 & 1.237 & $22.686^{*}$ & 3.877 & $72.199^{*}$ \\
\hline & & $(2.353)$ & $(8.062)$ & (3.444) & $(8.685)$ \\
\hline & 6 & 1.157 & $26.494^{*}$ & 4.465 & $67.883^{*}$ \\
\hline & & $(2.860)$ & $(9.892)$ & $(4.406)$ & (10.659) \\
\hline & 12 & 1.173 & $25.263^{*}$ & 4.488 & $69.075^{*}$ \\
\hline & & $(3.350)$ & $(9.945)$ & $(4.921)$ & (11.228) \\
\hline & 18 & 1.361 & $25.382^{*}$ & 4.368 & $68.887 *$ \\
\hline & & (3.416) & $(9.788)$ & $(4.858)$ & $(11.212)$ \\
\hline & 24 & 1.512 & $26.065^{*}$ & 4.307 & $68.114 *$ \\
\hline & & (3.488) & $(9.814)$ & $(4.789)$ & $(11.281)$ \\
\hline CV_MATERIALS & 1 & 0.284 & $17.943^{*}$ & 3.921 & $77.850^{*}$ \\
\hline & & (1.354) & $(6.033)$ & $(3.031)$ & $(6.261)$ \\
\hline & 3 & 0.861 & $30.029^{*}$ & 3.800 & $65.308^{*}$ \\
\hline & & $(2.141)$ & $(8.812)$ & $(3.635)$ & (8.973) \\
\hline & 6 & 1.256 & $35.689^{*}$ & 5.061 & $57.992 *$ \\
\hline & & (2.897) & (10.181) & $(5.106)$ & (10.357) \\
\hline & 12 & 1.332 & $34.819^{*}$ & 5.463 & $58.384 *$ \\
\hline & & (3.304) & (10.447) & $(5.935)$ & (11.127) \\
\hline & 18 & 1.494 & $34.907^{*}$ & 5.361 & $58.235^{*}$ \\
\hline & & (3.366) & (10.319) & $(5.880)$ & (11.235) \\
\hline & 24 & 1.654 & $35.189^{*}$ & 5.328 & $57.827^{*}$ \\
\hline & & (3.437) & (10.279) & $(5.484)$ & (11.227) \\
\hline CV_OIL\&GAS & 1 & 0.520 & $23.749 *$ & 7.231 & $68.498 *$ \\
\hline & & $(1.532)$ & $(6.108)$ & (3.595) & $(6.223)$ \\
\hline & 3 & 1.181 & $36.733^{*}$ & 7.064 & $55.020 *$ \\
\hline & & (2.187) & $(8.685)$ & $(4.613)$ & $(8.404)$ \\
\hline & 6 & 1.848 & $43.495^{*}$ & 7.651 & $47.004 *$ \\
\hline & & (3.353) & (10.351) & $(5.731)$ & (9.674) \\
\hline & 12 & 2.094 & $42.875^{*}$ & 8.006 & $47.023^{*}$ \\
\hline & & (3.797) & $(10.630)$ & $(6.231)$ & (10.286) \\
\hline & 18 & 2.151 & $42.849^{*}$ & 7.925 & $47.072 *$ \\
\hline & & (3.794) & (10.497) & $(6.143)$ & (10.319) \\
\hline & 24 & 2.220 & $43.012^{*}$ & 7.895 & $46.871^{*}$ \\
\hline & & (3.834) & (10.404) & $(6.097)$ & (10.306) \\
\hline CV_RETAIL & 1 & 0.754 & $13.153^{*}$ & 1.055 & $85.036^{*}$ \\
\hline & & (1.813) & $(5.311)$ & $(1.729)$ & $(5.790)$ \\
\hline & 3 & 1.640 & $22.100^{*}$ & 0.574 & $75.684^{*}$ \\
\hline & & $(2.847)$ & $(8.121)$ & $(1.923)$ & $(8.359)$ \\
\hline & 6 & 1.698 & $25.006^{*}$ & 0.631 & $72.663 *$ \\
\hline & & $(3.052)$ & $(9.695)$ & $(2.672)$ & $(9.952)$ \\
\hline & 12 & 1.660 & $24.523^{*}$ & 0.626 & $73.189 *$ \\
\hline & & (3.316) & (9.997) & (3.316) & (10.478) \\
\hline
\end{tabular}




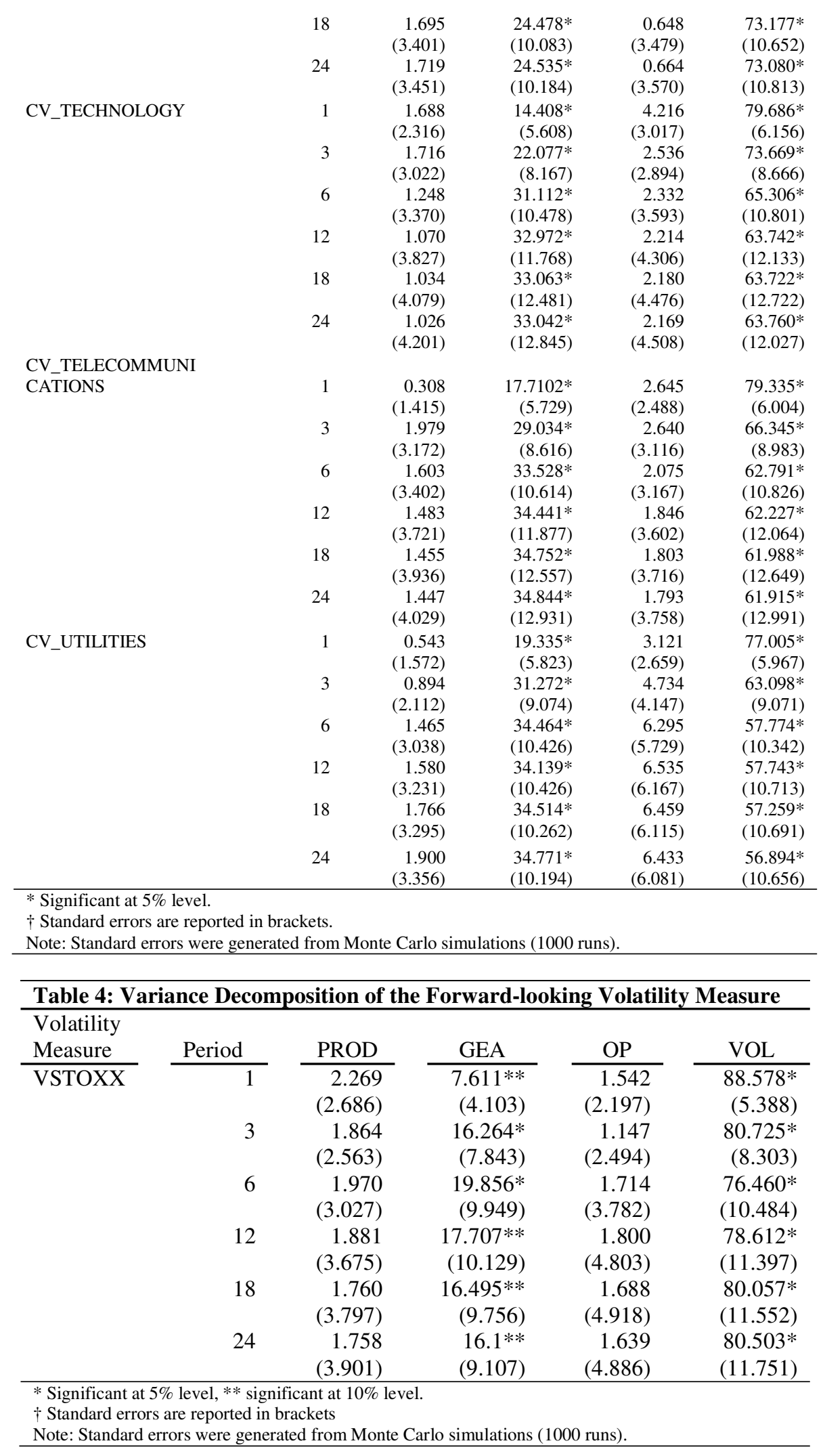




\title{
The effects of oil price shocks on stock market volatility: Evidence from European data
}

\author{
Stavros Degiannakis ${ }^{1}$, George Filis ${ }^{2}$, Renatas Kizys ${ }^{3}$ \\ ${ }^{1,3}$ University of Portsmouth \\ Department of Economics \\ Richmond Building, Portland Street, PO1 3DE \\ Portsmouth, UK \\ ${ }^{2}$ Bournemouth University \\ Department of Accounting, Finance and Economics \\ Executive Business Centre, \\ 89 Holdenhurst Road, BH8 8EB \\ Bournemouth, UK
}

*corresponding author: gfilis@bournemouth.ac.uk, tel:+44 1202968739 , fax:+44 1202968833

The paper investigates the effects of oil price shocks on stock market volatility in Europe by focusing on three measures of volatility, i.e. the conditional, the realized and the implied volatility. The findings suggest that supply-side shocks and oil specific demand shocks do not affect volatility, whereas, oil price changes due to aggregate demand shocks lead to a reduction in stock market volatility. More specifically, the aggregate demand oil price shocks have a significant explanatory power on both current- and forwardlooking volatilities. The results are qualitatively similar for the aggregate stock market volatility and the industrial sectors' volatilities. Finally, a robustness exercise using short- and long-run volatility models supports the findings.

JEL: C13, C32, G10, G15, Q40

Keywords: Conditional Volatility, Realized Volatility, Implied Volatility, Oil Price Shocks, SVAR

\section{INTRODUCTION AND BRIEF REVIEW OF THE LITERATURE}

There is a consensus among academics and practitioners that oil and stock markets are often intertwined with the global economic activity. Ascertaining exact nature and sources of the linkage between oil and stock markets and the global economic activity has proved to be a promising area for researchers over the last few decades. The research interest mainly concentrates either on the impact of oil prices on stock market developments or the effects of oil prices on the economy. Adding to this literature, the main objective of the paper is to research into the effects of three oil price shocks (namely, supply side shocks, aggregate demand shocks and oil specific demand shocks) on stock market volatility, with particular reference in the European stock market.

The seminal paper by Jones and Kaul (1996) was among the first to reveal a negative relationship between the oil prices and stock market returns. In addition, Sadorsky (1999) concludes that oil price changes are important determinants of stock market returns. In particular, he shows that stock markets respond negatively to a positive oil price change. Filis (2010), Chen (2009), Miller and Ratti (2009), Park and Ratti (2008), Driesprong et al. (2008) and Gjerde and Sættem (1999) second these findings by Sadorsky (1999) and Jones and Kaul (1996). 
The aforementioned negative relationship does not hold for stock markets operating in oil-exporting countries. Arouri and Rault (2012) show that for the oil-exporting countries, there is a positive relationship between oil price shocks and stock market returns. Other authors, though, do not find any relationship between oil price shocks and stock market returns (Jammazi and Aloui, 2010; Cong et al., 2008; Haung et al., 1996). Filis et al. (2011) provide an extensive review of the literature in the particular area.

Studies particularly focused on the European stock markets reveal that positive oil price changes tend to negatively affect stock returns; nevertheless, the exact relationship depends on the sector. In particular, oil-related stock market sectors tend to appreciate in the event of a positive oil price change, whereas the reverse holds for oil-intensive sectors (see, for example, Scholtens and Yurtsever, 2012; Arouri, 2011; Arouri and Nguyen, 2010).

Furthermore, a strand of the literature distinguishes the effects of oil price shocks on stock market activity according to their origin. Hamilton (2009a,b) and Kilian (2007a,b), in particular, suggest that different shocks in the oil market have different effects on stock markets. Kilian (2009) provides evidence that the response of aggregate stock returns differs depending on the cause of the oil price shock. Hamilton $(2009 a, b)$ disaggregates oil price shocks into two components, namely, the demand-side oil price shocks (which are caused by increased aggregate demand, e.g. due to the industrialization of China) and supply-side oil prices shocks (which are caused by alteration in the world oil production). In addition, Kilian (2009) identifies a third origin, the precautionary demand shocks or oil specific demand shocks. These are oil price shocks that are related with the uncertainty of the future availability of oil.

Baumeister and Peersman (2012), Basher et al. (2012), Kilian and Lewis (2011), Filis et al. (2011), Lippi and Nobili (2012), Kilian and Park (2009), Apergis and Miller (2009), Lescaroux and Mignon (2008), Kilian (2008) and Barsky and Kilian (2004) also illustrate the importance of taking into consideration the origins of the oil price shock in this area of interest. For example, Hamilton $(2009$ a,b) maintain that oil price shocks are mainly demand driven in the last decades and thus supply-side events do not exercise significant effects in oil prices. Lippi and Nobili (2012) proponent that supply-side oil price shocks have a negative effect in the economy, whereas the opposite is observed for the demand-side oil price shocks. In addition, Kilian and Park (2009) demonstrate that the supply-side oil price shocks do not have any effects on stock market returns, whereas stock markets tend to react negatively to oil specific demand shocks. On the other hand, they find that aggregate demand oil price shocks trigger a positive response from the stock markets. In the same line of reasoning, Filis et al. (2011) find evidence that the supply-side shocks do not seem to impact stock market returns, whereas the reverse holds for the demandside shocks. Similarly, Basher et al. (2012) show that supply-side oil price shocks do not exercise an impact on the emerging stock market returns, whereas the aggregate demand oil price shocks seem to have a positive effect. Finally, they find evidence that the oil specific demand shocks put downward pressure on stock returns.

Despite the fact that evidence proposes that the origin of the oil price shock triggers different responses from the stock markets, the majority of the literature does not consider them when examines its effects (see, inter alia, Arouri and Rault, 2012; Arouri and Nguyen, 2010; Bjørnland, 2009; Chen, 2009; Park and Ratti, 2008).

As aforementioned, the aim of this paper is to direct the attention of the research on the effects of the oil price shocks on stock market volatility. Studies in the early 80s and 90s (see, for example, Pindyck, 1991 and Bernanke, 1983, among others) reveal that increased energy prices generate uncertainty to firms, resulting in the delay of investment decisions. Furthermore, some authors opine 
that oil price innovations exercise an impact on aggregate uncertainty and they have significant negative effects on investments (see, inter alia, Ratti et al., 2011; Rahman and Serletis, 2011; Elder and Serletis, 2010). In addition, Bloom (2009) documents that stock market uncertainty increases after major shocks, such as the 2001 terrorist attack in US, OPEC oil supply disruptions, etc. Nevertheless, these studies have not considered the origins of the oil price shocks. We argue, though, that Bloom's choice of major shocks coincides with events that trigger certain oil price shocks, as these have been identified by Hamilton (2009a,b) and Kilian (2009, 2007a,b). For example, the 2001 terrorist attack in US triggered an oil specific demand shock, whereas OPEC oil supply disruptions cause supply-side oil price shocks. Thus, disentangling oil price shocks is of importance in understanding better stock market uncertainty.

In addition, the literature has well established that the aforementioned firm's uncertainty and aggregate uncertainty can be represented by individual stock price volatility and stock market volatility, respectively (see, for example, Baum et al., 2010 and Bloom, 2009).

Even though the characteristics of stock market volatility have been studied extensively in the past, ${ }^{1}$ the literature remains silent on the effects of the different oil price shocks on stock market volatility. Rather, a plethora of research output centers its attention solely on spillover effects between the oil price volatility and stock market returns and volatility or the relationship between oil price volatility and firm investments. ${ }^{2}$ This paper comes to fill this void.

More specifically, the contribution of the paper is threefold. First, it contributes to the literature that studies the effects of three different oil price shocks - oil supply shock, aggregate demand shock and oil specific demand shock $^{3}$ - on the stock market. Unlike previous studies that examine the response of stock returns on oil price shocks, we investigate the response of stock market volatility, as a measure of uncertainty of stock market investments, using a Structural VAR model. Second, we provide evidence from both aggregate stock market indices and industrial sector indices, as according to Arouri et al. (2012, p.2) "the use of equity sector indices is, in our opinions, advantageous because market aggregation may ask the characteristics of various sectors". Third, in contrast to studies that mainly focus on the responses of stock market returns in individual countries in Europe or in the US (Arouri, 2011; Arouri and Nguyen, 2010 and Scholtens and Yurtsever, 2012 are notable exceptions), emphasis of this research is placed on the pan-European stock market.

In light of empirical evidence that underlines the relative importance of the demand-driven oil price shocks, we expect stock market volatility in Europe to be more sensitive to the aggregate demand shock and the oil specific demand shock than to the supply-side shock.

Three volatility measures are utilized; conditional volatility, realized volatility and implied volatility. The conditional volatility, estimated from a predefined ARCH model, is the most widely applied method of quantifying volatility in financial time series. The realized volatility, introduced by Andersen and Bollerslev (1998), sums the high frequency squared log-returns to generate a lower frequency volatility measure. According to Ebens (1999), among others, the use of high frequency data for computing volatility at a lower frequency provides more accurate estimates of volatility. Implied volatility derives from the option pricing.

\footnotetext{
${ }^{1}$ See, among others, Xekalaki and Degiannakis (2010), Becker et al. (2007), Andersen et al. (2005a), Andersen et al. (2001) and Bollerslev et al. (1992).

${ }^{2}$ See, inter alia, Arouri et al. (2012), Henriques and Sadorsky (2011), Sadorsky (2011), Arouri et al. (2011), Vo (2011), Malik and Ewing (2009), Chiou and Lee (2009).

${ }^{3}$ Definitions of these shocks can be found in Kilian and Park (2009).
} 
The conditional volatility was chosen because it is the most generally applied measure of variance. The use of realized volatility measure is justified by the recent findings in financial literature that it provides more accurate estimates of volatility. On the other hand, the use of implied volatility is motivated by the fact that part of the literature illustrates that this type of volatility (a forward-looking measure) is more informational efficient compared to other volatility estimates, which represent the current-looking measures of volatility. ${ }^{4}$

Thus, it is important to identify any differences in their responses to oil price shocks. Koopman et al. (2005) propose that both implied volatility and realized volatility are informationally accurate. Conversely, authors such as Becker et al. (2007) and Corrado and Truong (2007) suggest that implied volatility indices do not provide any incremental information compared to other volatility indices. Engle (2002), though, argues that there is not a simple answer as to which volatility measure is the most accurate, as it depends upon the statistical approach adopted for the evaluation of forecasts.

We provide evidence that supply-side shocks and oil specific demand shocks do not affect stock market volatility, whereas, oil price changes due to aggregate demand shocks lead to a reduction in stock market volatility. The results hold for the industrial sectors' volatilities, as well. Prominent among our results is the finding that oil price shocks have a qualitatively similar impact for both the current-looking volatility measures and the implied volatility, which is a forward-looking measure.

The rest of the paper is organized as follows: Section 2 presents the volatility measures and the model used, Section 3 describes the dataset, Section 4 presents the empirical findings of the research and Section 5 concludes the study.

\section{METHODOLOGY}

In the next section three measures of volatility are defined, i.e. conditional volatility, realized volatility and implied volatility, whereas in section 2.2 the Structural VAR model is presented.

\subsection{Volatility Estimates}

According to the literature there are three main frameworks for measuring volatility. The first two correspond to the current market volatility measures, whereas the third is a forward-looking measure of volatility. In this paper we examine all these three volatility estimates.

The conditional volatility is the conditional standard deviation of the asset returns given the most recently available information. The conditional variance process of $y_{t}$ can be defined as $V\left(y_{t} \mid I_{t-1}\right) \equiv V_{t-1}\left(y_{t}\right) \equiv \sigma_{t}^{2}$, for $I_{t-1}$ denoting the information set investors know when they make their investment decisions at time $t-1$.

The realized volatility is based on the idea of using high frequency data to compute measures of volatility at a lower frequency, i.e. using hourly logreturns to generate a measure of daily volatility. By the term monthly realized volatility we denote the daily estimate of monthly variance.

Implied volatility is the instantaneous standard deviation of the return on the underlying asset, which would have to be input into a theoretical pricing model in order to yield a theoretical value identical to the price of the option in the marketplace, assuming all other inputs are known.

${ }^{4}$ See for example Blair et al. (2001), Christensen and Prabhala (1998), Fleming (1998) and Day and Lewis (1992). 


\subsubsection{Conditional Volatility}

The conditional variance of the daily log-returns process, $y_{t}$, is estimated with Ding's et al. (1993) APARCH model. The APARCH model has an appealing feature that it allows nesting tests of different types of asymmetry and functional forms (Hentschel, 1995). For instance, Laurent (2004) argues that the APARCH model nests at least seven GARCH specifications. The asymmetric power ARCH, or APARCH model is estimated assuming that the demeaned daily log-returns are conditionally Student-t distributed: ${ }^{5}$

$$
\begin{gathered}
y_{t}=c_{0}+\varepsilon_{t} \\
\varepsilon_{t}=\sigma_{t} z_{t} \\
\sigma_{t}^{\delta}=a_{0}+a_{1}\left(\left|\varepsilon_{t-1}\right|-\gamma_{1} \varepsilon_{t-1}\right)^{\delta}+b_{1} \sigma_{t-1}^{\delta} \\
z_{t}^{\text {i.i.d. }} \sim T(0,1 ; v) \\
f_{(t)}\left(z_{t} ; v\right)=\frac{\Gamma((v+1) / 2)}{\Gamma(v / 2) \sqrt{\pi(v-2)}}\left(1+\frac{z_{t}^{2}}{v-2}\right)^{-\frac{v+1}{2}},
\end{gathered}
$$

where $a_{0}>0, \delta>0, b_{1} \geq 0, a_{1} \geq 0$ and $-1<\gamma_{1}<1, v>2$.

The APARCH model with Student-t distributed standardized innovations accounts for i) volatility clustering, ii) power transformation of the conditional variance, iii) asymmetric and leptokurtic unconditional distribution of log-returns, and iv) asymmetric conditional distribution of log-returns. Therefore, it is considered as of the most successfully applied model in estimating conditional volatility. For technical details, the reader is referred to Xekalaki and Degiannakis (2010).

The monthly conditional volatility is computed by summing the $\tau$ daily conditional variance. Therefore, the annualized conditional volatility of month $t$, or $C V_{t}^{(m)}$, is computed as the square root of the sum of the conditional variances from the $16^{\text {th }}$ of the previous month up to and including the 15 th of the current month: ${ }^{6}$

$$
C V_{t}^{(m)}=100 \sqrt{12 \sum_{j=1}^{\tau} \sigma_{t_{j}}^{2}}
$$

where $\sigma_{t_{j}}^{2}$ denotes the daily conditional variance for the $j=1, \ldots, \tau$ trading days of month $t$.

\subsubsection{Realized Volatility}

Merton (1980) was the first who noted the idea of using high frequency data to compute measures of volatility at a lower frequency. The concept of the realized volatility is based on the integrated volatility, $\sigma_{[a, b]}^{2(I V)}=\int_{a}^{b} \sigma^{2}(t) d t$. Financial literature assumes that the instantaneous logarithmic price, $\log p(t)$,

\footnotetext{
${ }^{5}$ The incorporation of a first-order autoregressive term, AR(1), in the conditional mean, provides qualitative similar results.

${ }^{6}$ The use of the daily observations from the $16^{\text {th }}$ of the previous month up to the $15^{\text {th }}$ of the current month is justified by the availability of the monthly data on the $15^{\text {th }}$ of each month.
} 
of a financial asset follows a diffusion process, $d \log p(t)=\sigma(t) d W(t)$, where $\sigma(t)$ is the volatility of the instantaneous log-returns process and $W(t)$ is the standard Wiener process. Theory of quadratic variation of semi-martingales provides consistent estimate of integrated volatility by the realized variance,

$R V_{[a, b]}=\sum_{j=1}^{\tau}\left(\log P_{t_{j}}-\log P_{t_{j-1}}\right)^{2}$, assuming that the time interval $[a, b]$ is partitioned in $\tau$ equidistance points in time; see Andersen et al. (2003) and Barndorff-Nielsen and Shephard (2002).

For present study's purposes we measure the monthly realized volatility, partitioning the monthly time interval in daily equidistance points in time, for $\tau$ denoting the number of trading days. Therefore, the annualized realized volatility of month $t$, or $R V_{t}^{(m)}$, is computed as the square root of the sum of the squared daily log-returns from the 16th of the previous month up to the 15 th of the current month:

$$
R V_{t}^{(m)}=100 \sqrt{12 \sum_{j=1}^{\tau}\left(\log P_{t_{j}}-\log P_{t_{j-1}}\right)^{2}} .
$$

We estimate monthly volatility by summing up daily volatility. However, this measure would be biased by the number of trading days in the month. That is, volatility in the month with more trading days would be greater than volatility in any other month, even the volatility does not change. In order to check the robustness of the results, we also estimate $R V_{t}^{(m)}$ by scaling each month's volatility with $\sqrt{22 / \tau}$, assuming equal number of trading days for each month. The results remain qualitatively similar.

\subsubsection{Implied Volatility Index - VSTOXX}

Studies, see i.e. Blair et al. (2001), characterize implied volatility measures are less informative than volatility estimated from asset returns, because they induce biases and contain mis-specification problems. In 1993, the Chicago Board of Options Exchange published the first implied volatility index. The computation of implied volatility indices takes into account the latest advances in financial theory, eliminating measurement errors that had characterized the implied volatility measures.

Market participants consider the implied volatility index as an important tool for measuring investors' sentiment. Investors and risk managers refer to volatility indices as fear index or investor fear gauge. The VSTOXX Volatility Index (which is the volatility index for the Eurostoxx 50 Index, also named as EURO STOXX 50 Volatility Index) measures the implied variance across all options of a given time to expiry. The main index is designed as a rolling index at a fixed 30 days to expiry. This is achieved using linear interpolation of the two nearest of the eight available sub-indices. The index is calculated based on eight expiry months with a maximum time to expiry of two years.

The annualized implied volatility of month $t$, or $\operatorname{VSTOXX} X_{t}^{(m)}$, is computed as the average of the daily $\operatorname{VSTOXX} t_{j}$ from the $16^{\text {th }}$ of the previous month up to the $15^{\text {th }}$ of the current month:

$$
\operatorname{VSTOXX}_{t}^{(m)}=\sqrt{\tau}^{-1} \sqrt{\sum_{j=1}^{\tau} \operatorname{VSTOXX}_{t_{j}}^{2}}
$$


where $V_{S T O X X}$ denotes the daily implied volatility for the $j=1, \ldots, \tau$ trading days of month $t$. VSTOXX index is based on option prices and it is constructed by STOXX limited. ${ }^{7}$

\subsection{Structural VAR Model}

Using a Structural VAR framework, we examine the effects of three oil prices shocks on stock market volatility (VOL). Namely, the oil price shocks are the supply-side shocks, aggregate demand shocks and oil specific demand shocks, as these are identified from changes in world oil production (PROD), global economic activity (GEA) and changes in oil prices (OP), respectively. VOL is the generic name of the volatility series. For each SVAR model the volatility variable will be named after the method of estimation (i.e. conditional, realized or implied volatility) and the name of the index (either aggregate or industrial). ${ }^{8}$

The structural representation of the VAR model of order $p$ takes the following general form:

$$
\mathbf{A}_{0} \mathbf{y}_{t}=\mathbf{c}_{0}+\sum_{i=1}^{p} \mathbf{A}_{i} \mathbf{y}_{t-i}+\boldsymbol{\varepsilon}_{t}
$$

where, $\mathbf{y}_{t}$ is a $[4 \times 1]$ vector of endogenous variables, i.e. $\mathbf{y}_{t}=\left[P R O D_{t}, G E A_{t}, O P_{t}, V O L_{t}\right], \mathbf{A}_{0}$ represents the $[4 \times 4]$ contemporaneous matrix, $\mathbf{A}_{i}$ are [4x4] autoregressive coefficient matrices, $\boldsymbol{\varepsilon}_{\mathrm{t}}$ is a $[4 \times 1]$ vector of structural disturbances, assumed to have zero covariance and be serially uncorrelated. The covariance matrix of the structural disturbances takes the following form $E\left[\boldsymbol{\varepsilon}_{t} \boldsymbol{\varepsilon}_{t}^{\prime}\right]=\mathbf{D}=\left[\begin{array}{llll}\sigma_{1}^{2} & \sigma_{2}^{2} & \sigma_{3}^{2} & \sigma_{4}^{2}\end{array}\right] \times \mathbf{I}$. In order to get the reduce form of our structural model (1) we multiply both sides with $\mathbf{A}_{0}^{-1}$, such as that:

$$
\mathbf{y}_{t}=\mathbf{a}_{0}+\sum_{i=1}^{p} \mathbf{B}_{i} \mathbf{y}_{t-i}+\mathbf{e}_{t}
$$

where, $\mathbf{a}_{0}=\mathbf{A}_{0}^{-1} \mathbf{c}_{0}, \mathbf{B}_{i}=\mathbf{A}_{0}^{-1} \mathbf{A}_{i}$, and $\mathbf{e}_{t}=\mathbf{A}_{0}^{-1} \boldsymbol{\varepsilon}_{t}$, i.e. $\boldsymbol{\varepsilon}_{t}=\mathbf{A}_{0} \mathbf{e}_{t}$. The reduced form errors $\mathbf{e}_{t}$ are linear combinations of the structural errors $\boldsymbol{\varepsilon}_{t}$, with a covariance matrix of the form $E\left[\mathbf{e}_{t} \mathbf{e}_{t}^{\prime}\right]=\mathbf{A}_{0}^{-1} \mathbf{D} \mathbf{A}_{0}^{-1^{\prime}}$.

The structural disturbances can be derived by imposing suitable restrictions on $\mathbf{A}_{0}$. The following short-run restrictions are imposed in the model:

$$
\left[\begin{array}{c}
\varepsilon_{1, t}^{S S} \\
\varepsilon_{2, t}^{A D S} \\
\varepsilon_{3, t}^{O S S} \\
\varepsilon_{4, t}^{V S}
\end{array}\right]=\left[\begin{array}{cccc}
a_{11} & 0 & 0 & 0 \\
a_{21} & a_{22} & 0 & 0 \\
a_{31} & a_{32} & a_{33} & 0 \\
a_{41} & a_{42} & a_{43} & a_{44}
\end{array}\right] \times\left[\begin{array}{c}
e_{1, t}^{P R O D} \\
e_{2, t}^{G E A} \\
e_{3, t}^{O P} \\
e_{4, t}^{V O L}
\end{array}\right]
$$

where $\mathrm{SS}=$ supply-side shocks, $\mathrm{ADS}=$ aggregate demand shock, OSS=oil specific demand shock and VS=volatility shock.

The restrictions in the model are explained as follows. The oil production is not responding contemporaneously to an increase/decrease of oil

\footnotetext{
${ }^{7}$ The interested reader can find all the necessary information about volatility index in the following link: http://www.stoxx.com/indices/index_information.html?symbol=V2TX.

${ }^{8}$ For example, the realized volatility of the industrial sector will be named RV_INDUSTRIAL.
} 
demand, caused by higher/lower economic activity, due to the adjustment costs of oil production. However, oil supply disruption (supply-side shock) can influence the global economic activity, the price of oil and the stock market volatility, within the same month. The global economic activity is not contemporaneously influenced by oil prices due to the time that is required for the world economy to react. On the contrary, an aggregate demand shock will have an immediate impact on oil prices and stock market volatility, considering the reaction time of the commodities and financial markets. Turning to the oil price innovation, any increase in the price can be driven by supply-side event, aggregate demand-side events, as well as, oil specific demand events. Thus, oil production shocks, as well as, aggregate demand shocks can contemporaneously trigger responses from the oil prices. In highly liquid markets as the European market, the stock market volatility reacts contemporaneously to all aforementioned oil price shocks.

To proceed to the estimation of the reduced form of model (1), it is first necessary to establish the stationarity of the variables. The ADF and PP unit root tests suggest that all variables are $\mathrm{I}(0)$. The lag length of the VAR model was identified using the Akaike Information Criterion (AIC). The AIC selects a VAR model with four lags. ${ }^{9}$

\section{DATA DESCRIPTION}

In order to estimate the volatility figures we use daily data from January 1999 to December 2010 on aggregate European stock market indices. In particular, the stock market index used is Eurostoxx 50, which is Europe's leading blue chips stock market index and the data have been extracted from Datastream $^{\circledR}$. In addition, we consider the following industrial sectors indices, which have been constructed by Dow Jones: Financials, Oil\&Gas, Retail, Consumption Goods, Health, Industrial, Basic Materials, Technology, Telecommunications and Utilities. The industrial sector indices data have been extracted from Datastream ${ }^{\circledR}$. For consistency purposes we have also considered the pan-European stock market index constructed by Dow Jones. As mentioned in section 2.1 once the daily volatility figures have been estimated, we then convert them into monthly figures.

Furthermore, we use monthly data for the same time period for oil production, oil prices and global economic activity. Brent crude oil is chosen, as a proxy of world oil price, due to the fact that this type of oil represents the $60 \%$ of the world oil daily consumption (Maghyereh, 2004). We use oil production data, as a proxy for oil supply. Both Brent crude oil price and oil production data have been extracted from the Energy Information Administration. Finally, we adopt Kilian's (2009) measurement of the global economic activity based on dry cargo freight rates. ${ }^{10}$ Prices are expressed in dollar terms and are transformed in log-returns.

Figure 1 presents the volatility measures for the Eurostoxx 50 index (realized volatility-RV_STOXX50, conditional volatility-CV_STOXX50 and implied volatility-VSTOXX), the growth rate of the world oil production, the global economic activity and the oil price returns. ${ }^{11}$

\section{[FIGURE 1 HERE]}

\footnotetext{
${ }^{9}$ Results are available upon request. The SVAR models do not suffer from autocorrelation and no inverse roots of the characteristic polynomial lie outside the unit circle. Thus, we conclude that the SVAR models satisfy the stability condition.

${ }^{10}$ The data can be found in Lutz Kilian personal website (http://www-personal.umich.edu/ lkilian/)

${ }^{11}$ The volatility graphs for the pan-European stock market index and the industrial sectors indices are available upon request.
} 
It is immediately apparent that volatility (in all three expressions) reaches a peak near the end of 2008 and again in May 2010. These periods coincide with the world financial crisis and the Greek debt crisis, respectively. Similar patterns are observed in the volatility measures of the pan-European stock market index by Dow Jones and of all industrial sectors' indices (not presented visually here, though). During 2008, we also observe a trough in the global economic activity and extreme negative returns for the oil prices. This period has been also characterized by demand driven oil price shocks. These preliminary findings may suggest that stock market volatility responds heavily to demand driven oil price shocks. Nevertheless, the impulse responses from the SVAR model will provide us with a clearer picture.

Furthermore, Table 1 presents some descriptive statistics for the volatility measures of the Eurostoxx 50 index and the three oil variables. The mean values of the realized volatility and conditional volatility are very close, whereas the VSTOXX mean value is higher. In addition, all volatility measures exhibit a significant variation over time which is evident by the minimum, maximum and standard deviation statistics. Naturally, the volatility measures are positively skewed and leptokurtic.

\section{[TABLE 1 HERE]}

As far as the oil variables are concerned, the global economic activity is the most volatile one, followed by the oil price returns. Both variables are negatively skewed, whereas the oil production growth rates are positively skewed. The skewness measures suggest that there are more negative oil logreturns and changes in the global economic activity, whereas the oil production exhibits more positive returns.

\section{ESTIMATION RESULTS}

The purpose of the SVAR model is to examine the dynamic adjustments of each of the variables to exogenous stochastic structural shocks (see, inter alia, Bjørnland and Leitemo, 2009; Kilian and Park, 2009). Thus, next we present the SVAR model findings for the volatility indices of the Eurostoxx50 and the industrial sectors in terms of the impulse response functions (IRF) and the variance decomposition. ${ }^{12}$

Section 4.1 describes the estimation results based on current-looking measures of stock market volatility (conditional and realized volatilities). The results on the aggregate stock market and industrial sector indices are summarized in Sections 4.1.1 and 4.1.2, respectively. Section 4.2 describes the estimation results based on the forward-looking measure of stock market volatility (implied volatility). Section 4.3 summarizes the robustness checks.

\subsection{Current-looking Volatility Measures}

\subsubsection{Aggregate European Stock Market Indices}

The impulse responses (Figure 2) depict that the reaction of the volatility measures of the Eurostoxx 50 index on the three oil shocks differ quite substantially.

\section{[FIGURE 2 HERE]}

\footnotetext{
${ }^{12}$ The SVAR results for the pan-European stock market index constructed by Dow Jones ${ }^{\circledR}$ are qualitatively similar and thus they are not presented here. They are available upon request.
} 
Changes in world oil production do not exercise any significant impact on stock market volatility. The argument that the OPEC's decisions on oil production levels do not impact stock markets nowadays, finds support here. Thus, this finding does not come with a surprise. Furthermore, the fact that stock market volatility is not reacting to supply-side oil prices shocks complements the evidence provided by Basher et al. (2012), Filis et al. (2011) and Kilian and Park (2009), who argue that changes in oil production do not affect stock price returns. Similar observation can be made for the oil specific demand shock, as its effect is not significant on any volatility measure. A plausible explanation of this result lies in the nature of firms' responses to oil price changes. We argue that firms, nowadays, engage in effective hedging strategies which reduce the effects of adverse oil price movements (Arouri, 2011), mainly caused by idiosyncratic oil price shocks (or oil specific demand shocks). On the contrary, increases in world's aggregate demand, which implies increased economic activity, tend to reduce stock market volatility, as expected. A positive aggregate demand shock can be regarded as good news to the stock market. In the event of a positive aggregate demand shock, uncertainty about future cash flows decreases, driving down stock market volatility. One can also argue that positive news about global economic activity is associated with a more stable business environment, which, in turn, reduces the uncertainty in the market. From an opposite angle, Bloom (2009) has shown that negative news about the global economic activity, such as those during the Asian crisis in 1997 and the credit crunch in 2008 , tend to increase stock market volatility. In general, stock markets tend to respond favorably when the world economic developments are positive. The preliminary findings had already provided with an initial idea about the inverse link between aggregate demand oil price shocks and stock market volatility. Overall, the response is significant for about 6 months and dynamic convergence is achieved after 12 months after the shock, for both volatility measures.

In regard with the variance decomposition (Table 2), we observe that the effects of the supply-side and oil specific demand shocks are very small and insignificant, suggesting that these shocks do not exercise an impact on stock market volatility. Furthermore, the effects of the aggregate demand shocks are small and significant in the short-run; however their explanatory power exhibits an increasing pattern (remaining significant) as the forecasting window increases. This is suggestive of the fact that the aggregate demand shocks have a very important role in the European stock market volatility.

\section{[TABLE 2 HERE]}

In more detail, about $9 \%-18 \%$ (depending on the volatility measure) of the variation in the volatility of the Eurostoxx50 index is associated with the oil price shocks, during the first few months. In a period of 24 months a total of $24 \%-38 \%$ of the variability of the volatility is explained by the oil price shocks. The main contributor to this variability is the aggregate demand oil price shock in both volatility measures. Linking these findings with the evidence on stock market returns (see, for example, Kilian and Park, 2009; Hamilton, 2009a,b) it is suggested that supply-side shocks do not seem to influence any of the stock markets characteristics (i.e. returns and volatilities), whereas demand-side shocks - and in particular the aggregate demand oil price shocks - do.

Overall, the results suggest that increases in oil prices due to increased global economic activity (aggregate demand shock) reduce stock market volatility, as positive development is the global economic activity is regarded as positive information by the stock markets. 


\subsubsection{European Industrial Sectors}

Having analyzed the effects of the three oil shocks on the aggregate stock market volatility, we proceed to the analysis of these effects on the industrial sectors. $^{13}$

The impulse responses (Figure 3) suggest that the reaction of the volatility measures of the industrial sectors on the three oil shocks is similar to these of the Eurostoxx50 volatility measures. More specifically, the aggregate demand shock is exercising a significant negative effect on industrial sectors' volatility (the same result holds for both the realized volatility and the conditional volatility). The supply-side oil price shocks and the oil specific demand shocks do not seem to influence any of the sectors' realized or conditional volatilities. ${ }^{14}$

\section{[FIGURE 3 HERE]}

The only exemption is the Oil\&Gas sector. Both the realized and conditional volatility of the Oil\&Gas sector respond negatively to the two demand-side shocks (i.e. aggregate demand shock and oil specific demand shock). This finding is expected since any increase in oil price is received as positive news for the companies listed in the Oil\&Gas sector. The effects remain significant for about 3-4 months and they are fully absorbed after 8 to 10 months. It could be argued that supply-side shocks should also benefit the Oil\&Gas sector; nevertheless, we cannot find such evidence in this study.

Overall, the findings suggest that disruptions or increases in world oil production do not provide any information for the volatility of any sector, even the Oil\&Gas one. The opposite holds for the aggregate demand oil price shocks.

The variance decomposition analysis (Table 3) illustrates that the three oil price shocks exercise the highest influence on the RV_OIL\&GAS and CV_OIL\&GAS (about 53\%), as expected, and it is followed by the RV_CONSUMPTION and CV_CONSUMPTION (about 40\%). The latter is expected to be influenced heavily from the oil price shocks considering that Europe is mainly an oil importing region. Regarding the remaining industrial indices, the three oil price shocks explain about $10 \%-20 \%$ of the variability of their volatility. The lowest influenced is observed in the realized and conditional volatility of the Financials sector (about 10\%), suggesting that the Financials sector's volatility is mainly influenced by other variables, rather than the oil price shocks. The main contributor of this influence, in all cases, is the aggregate demand shock, a similar finding with the aggregate European stock market volatility. ${ }^{15}$

[TABLE 3 HERE]

\subsection{Forward-looking Volatility Measure}

The impulse responses (Figure 4) of the Eurostoxx 50 implied volatility (VSTOXX) measure is essential the same with those produced by the conditional and realized volatilities.

\section{[FIGURE 4 HERE]}

\footnotetext{
${ }^{13}$ The descriptive statistics and figures of the industrial sectors' volatility measures are available upon request.

${ }^{14}$ Figures for the impulse responses of the industrial sectors' realized volatilities are available upon request.

${ }^{15}$ The variance decomposition of the industrial sectors' realized volatilities is available upon request.
} 
Again, both supply-side oil price shocks and oil specific demand shocks do not exercise any significant impact on implied volatility, whereas positive aggregate demand oil price shocks trigger a negative response.

In terms of the variance decomposition (Table 4), we observe that the explanatory power of the three oil price shocks on implied volatility exhibits a peak in the medium-term and starts to decline thereafter until it reaches a stable level after 24 months.

\section{[TABLE 4 HERE]}

More specifically, in the first month about $9 \%$ of the variation in the implied volatility is associated with the oil price shocks, whereas in a period of 6-12 months this figure increases to an average of $22 \%$. The main contributor to this variability is the aggregate demand oil price shock, as also suggested by the conditional and realized volatilities.

Comparing the results among the three volatility measures, we observe that these measures provide qualitatively and quantitatively similar information. Hence, the implied volatility index (a forward-looking volatility measure) does not provide additional information compared to the conditional and realized volatility measures, which estimate the market volatility at the current time. This is a very interesting finding considering that several aforementioned studies have concluded that implied volatility indices provide superior information (see Xekalaki and Degiannakis, 2010; Becker et al., 2007; Andersen et al., 2005a; Andersen et al., 2001 and Bollerslev et al., 1992). Despite the fact that this result may come as a surprise, it does not remain without a possible explanation. It is worth noting that this result does not contradict the forward-looking feature of the implied volatility measure. The impulse responses of the current-looking volatility measures depict that the effects of the aggregate demand oil price shocks do not fade out immediately, but rather they require about 12 months to be fully absorbed. This means that the impact remains for the future months and this is what it is captured by the implied volatility response to the aggregate demand oil price shocks. The uncharacteristically prolonged response of the implied volatility is also artifact of its long memory, as documented in Section 4.3.

\subsection{Robustness Checks}

In order to test for the robustness of our results a battery of alternative approaches has been employed. ${ }^{16}$ More specifically, we estimate two volatility models (one with short memory and one with long memory) and we examine whether the aggregate demand oil price shock series has explanatory power on stock market volatility. The choice of the aggregate demand oil price shock series is justified by the fact that it was the only oil price shock that showed to have a significant effect on stock market volatility, based on the impulse response functions. Because stock market volatility is found invariant to the supply-side shock and the oil specific demand shock, we deliberately discard these two shocks from our robustness exercise.

First, we construct the aggregate demand oil price shock series (ADS). In order to achieve that we proceed to a historical decomposition of the effects of all three oil price shocks on the oil price returns.

The historical decomposition procedure can be summarized in three steps. In the first step, we estimate a structural VAR on changes in oil production, global economic activity and oil price returns, identifying the

\footnotetext{
${ }^{16}$ The detailed results from the short-and long memory volatility models are available from the authors upon request.
} 
supply-side shock, the aggregate demand shock and the oil specific demand shock, respectively. In a second step, we use the estimated VAR model to forecast the endogenous variables. In a third step, we decompose the forecast errors into the cumulative contributions of the structural oil-price shocks (see Burbidge and Harrison, 1985).

We then use the cumulative effect of the aggregate demand shocks $(A D S)$ on oil price log-returns as an explanatory variable in a short-and long memory volatility models. The estimation results suggest that $A D S$ exercises a negative and significant effect on stock market volatility. The results are qualitatively similar for the three volatility measures and for both the aggregate stock market and industrial sector indices. In particular, a positive aggregate demand shock causes a reduction in the stock market volatility, which confirms the findings of the SVAR model. The results are, thus, of particular importance as they could facilitate traders, investors, researchers or policy makers, should they need to forecast stock market volatility, price derivatives, manage risk and formulate regulation.

\section{CONCLUDING REMARKS}

The study examines the effects of three oil prices shocks (i.e., supplyside shock, aggregate demand shock and oil specific demand shock) on stock market volatility using a Structural VAR framework. We consider two volatility measures, namely the conditional volatility and the realized volatility, which measure the current stock market volatility. We also examine the effects of oil price shocks on implied volatility, as well, which is a forward-looking volatility measure.

We conclude that supply-side and oil specific demand shocks do not affect volatility, whereas, aggregate demand shocks influence volatility at a significant level. This finding holds for both the current-looking volatility and the implied volatility measures of aggregate stock market and industrial sector indices. Furthermore, the two volatility models (short- and long-memory models) verify the SVAR results, suggesting that the effect of the aggregate demand oil price shocks on volatility is negative and significant for all indices and all measures. The findings of the study are essential in pricing financial derivatives, selecting portfolios, measuring and managing investment risk. Investors, risk managers, even policy makers of Central Banks and Capital Market Commissions will find the outcomes of the study useful in handling market's uncertainty in relation with the state of the oil price shocks. For example, supervisors of financial institutions must hold capital based on its internal model's estimates of Value-at-Risk. The Value-at-Risk internal model can take into consideration the interrelation between oil price shocks and stock market volatility. Basel Committee, in order to strengthen bank capital requirements and introduce enhanced regulatory requirements on bank liquidity, may take advantage of the ability to model the relationship between aggregate demand oil price shocks and volatility of European stock markets.

It is essential that further studies will distinguish such effects for oilimporting and oil-exporting countries and conditional correlation models can be used to identify the aforementioned relationships in a time-varying environment. Finally, following Andersen et al. (2005b), an interesting question underpinning this research is whether and, if so, how the betas of European stock market sectors respond to different oil price shocks. 


\section{ACKNOWLEDGMENTS}

We would like to thank one editor Prof. Lester Hunt and the two anonymous referees for their constructive comments and suggestions which helped us to improve the scope and clarity of the paper. We thank the participants of the $10^{\text {th }}$ INFINITI Conference on International Finance and the $2^{\text {nd }}$ International Conference of the Financial Engineering and Banking Society for their comments and Prof. Robin Lumsdaine for her valuable suggestions. Dr. Stavros Degiannakis acknowledges the support from the European Community's Seventh Framework Programme (FP7-PEOPLE-IEF) funded under grant agreement no. PIEF-GA-2009-237022. The authors are solely responsible for any remaining errors and deficiencies.

\section{REFERENCES}

Andersen, T.G. and T. Bollerslev (1998). “Answering the Skeptics: Yes, Standard Volatility Models Do Provide Accurate Forecasts." International Economic Review 39(4): 885-905.

Andersen, T.G., T. Bollerslev, F.X. Diebold, and H. Ebens (2001). "The Distribution of Stock Return Volatility." Journal of Financial Economics 61(1): 43-76.

Andersen, T.G., T. Bollerslev, F.X. Diebold, and P. Labys (2003). "Modeling and Forecasting Realized Volatility.” Econometrica 71(2): 529-626.

Andersen, T.G., T. Bollerslev, and N. Meddahi (2005a). "Correcting the Errors: Volatility Forecast Evaluation Using High-frequency Data and Realized Volatilities." Econometrica 73(1): 279296.

Andersen, T.G., T. Bollerslev, F.X. Diebold, and J. Wu (2005b). "A Framework for Exploring the Macroeconomic Determinants of Systematic Risk." American Economic Review, Papers Proceedings of the One Hundred Seventeenth Annual Meeting of the American Economic Association 95(2): 398-404.

Apergis, N. and S.M. Miller (2009). "Do Structural Oil-Market Shocks Affect Stock Prices?" Energy Economics 31(4): 569-575.

Arouri, M.E.H. (2011). "Does Crude Oil Move Stock Markets in Europe? A Sector Investigation." Economic Modelling 28(4): 1716-1725.

Arouri, M.E.H. and D.K. Nguyen (2010). "Oil Prices, Stock Markets and Portfolio Investment: Evidence from Sector Analysis in Europe over the Last Decade.” Energy Policy 38(8): 45284539.

Arouri, M.E.H., J. Jouini and D.K. Nguyen (2011). "Volatility Spillovers between Oil Prices and Stock Sector Returns: Implications for Portfolio Management.” Journal of International Money and Finance 30(7): 1387-1405.

Arouri, M.E.H., J. Jouini and D.K. Nguyen (2012). "On the Impacts of Oil Price Fluctuations on European Equity Markets: Volatility Spillover and Hedging Effectiveness." Energy Economics 34(2): 611-617.

Arouri, M.E.H. and C. Rault (2012). "Oil Prices and Stock Markets in GCC Countries: Empirical Evidence from Panel Analysis.” International Journal of Finance and Economics 17(3): 242253.

Barndorff-Nielsen, O.E. and N. Shephard (2002). "Econometric Analysis of Realised Volatility and its Use in Estimating Stochastic Volatility Models." Journal of the Royal Statistical Society: Series B 64(2): 253-280.

Barsky, R. and L. Kilian (2004). "Oil and the Macroeconomy Since the 1970s." Journal of Economic Perspectives 18(4): 115-134.

Basher, S.A., A.A. Haug, and P. Sadorsky (2012). "Oil Prices, Exchange Rates and Emerging Stock Markets.” Energy Economics 34(1): 227-240.

Baum, C.F., M. Caglaynan, and O. Talavera (2010). "On the Sensitivity of Firms' Investment to Cash Flow and Uncertainty.” Oxford Economic Papers 62(2): 286-306.

Baumeister, C. and G. Peersman (2012). "Time-varying Effects of Oil Supply Shocks on the US Economy." Bank of Canada Working Paper Series, WP2012-02.

Becker, R., A.E. Clements, and S.I. White (2007). "Does Implied Volatility Provide Any Information Beyond That Captured in Model-based Volatility Forecasts?" Journal of Banking and Finance 31(8): 2535-2549.

Bernanke, B.S. (1983). "Irreversibility, Uncertainty, and Cyclical Investment." Quarterly Journal of Economics 98(1): 85-106

Bjørnland, H.C. (2009). "Oil Price Shocks and Stock Market Booms in an Oil Exporting Country." Scottish Journal of Political Economy 56(2): 232-254.

Bjørnland, H.C. and K. Leitemo (2009). "Identifying the Interdependence Between US Monetary Policy and the Stock Market.” Journal of Monetary Economics 56(2): 275-282.

Blair, B.J., S.-H. Poon, and S.J. Taylor (2001). "Forecasting S\&P100 Volatility: The Incremental 
Information Content of Implied Volatilities and High-frequency Index Returns." Journal of Econometrics 105(1): 5-26.

Bloom, N. (2009). "The Impact of Uncertainty Shocks.” Econometrica 77(3): 623-685.

Bollerslev, T., R.Y. Chou, and K.F. Kroner (1992). "ARCH Modeling in Finance: A Review of the Theory and Empirical Evidence.” Journal of Econometrics 52(1-2): 5-59.

Burbidge, J. and A. Harrison (1985). "A Historical Decomposition of the Great Depression to Determine the Role of Money." Journal of Monetary Economics 16(1): 45-54.

Chen, S.-S. (2009). "Do Higher Oil Prices Push the Stock Market Into Bear Territory?" Energy Economics 32(2): 490-495.

Chiou, J.-S. and Y.-H. Lee (2009). "Jump Dynamics and Volatility: Oil and the Stock Markets." Energy 34(6): 788-796.

Christensen, B.J. and N.R. Prabhala (1998). "The Relation Between Implied and Realised Volatility." Journal of Financial Economics 50(2): 125-150.

Corrado, C. and C. Truong (2007). "Forecasting Stock Index Volatility: Comparing Implied Volatility and the Intraday High-Low Price Range.” Journal of Financial Research 30(2): 201215.

Cong, R.-G., Y.-M. Wei, J.-L. Jiao, and Y. Fan (2008). "Relationships Between Oil Price Shocks and Stock Market: An Empirical Analysis From China.” Energy Policy 36(9): 3544-3553.

Day, T.E. and C.M. Lewis (1992). "Stock Market Volatility and the Information Content of Stock Index Options.” Journal of Econometrics 52(1-2): 267-287.

Ding, Z., C.W.J. Granger, and R.F. Engle (1993). "A Long Memory Property of Stock Market Returns and a New Model." Journal of Empirical Finance 1(1): 83-106.

Driesprong, G., B. Jacobsen, and B. Maat (2008). "Striking Oil: Another Puzzle?" Journal of Financial Economics 89(2): 307-327.

Ebens, H. (1999). "Realized Stock Volatility". Johns Hopkins University, Department of Economics, Working Paper, 420.

Elder, J. and A. Serletis (2011). "Oil Price Uncertainty". Journal of Money, Credit and Banking 42(6): 1137-1159.

Engle, R.F. (2002). "New Frontiers for ARCH Models". Journal of Applied Econometrics 17(5): $425-446$.

Filis, G. (2010). "Macro Economy, Stock Market and Oil Prices: Do Meaningful Relationships Exist Among Their Cyclical Fluctuations?" Energy Economics 32(4): 877-886.

Filis, G., S. Degiannakis, and C. Floros (2011). "Dynamic Correlation Between Stock Market and Oil Prices: The Case of Oil-importing and Oil-exporting Countries." International Review of Financial Analysis 20(3): 152-164.

Fleming, J. (1998). "The Quality of Market Volatility Forecasts Iimplied by S\&P 100 Index Option Prices." Journal of Empirical Finance 5(4): 317-345.

Gjerde, Ø. and F. Sættem (1999). "Causal Relations Among Stock Returns and Macroeconomic Variables in a Small, Open Economy." Journal of International Financial Markets, Institutions and Money 9(1): 61-74.

Hamilton, J.D. (2009a). “Understanding Crude Oil Prices.” Energy Journal, 30(2), 179-206.

Hamilton, J.D. (2009b). "Causes and Consequences of the Oil Shock of 2007-08." Brookings Papers on Economic Activity Spring 2009: 215-261.

Haung, R.D., R.W. Masulis, and H.R. Stoll (1996). "Energy Shocks and Financial Markets.” Journal of Futures Markets 16(1): 1-27.

Henriques, I. and P. Sadorsky (2011). "The Effect of Oil Price Volatility on Strategic Investment." Energy Economics 33(1): 79-87.

Hentschel, L. (1995). "All in the Family: Nesting Symmetric and Asymmetric GARCH Models." Journal of Financial Economics 39(1): 71-104.

Jammazi, R. and C. Aloui (2010). "Wavelet Decomposition and Regime Shifts: Assessing the Effects of Crude Oil Shocks on Stock Market Returns.” Energy Policy 38(3): 1415-1435.

Jones, M.C. and G. Kaul (1996). "Oil and the Stock Markets.” Journal of Finance 51(2): 463-491.

Kilian, L. (2008). "Exogenous Oil Supply Shocks: How Big Are They and How Much Do They Matter for the U.S. Economy?" Review of Economics and Statistics 90(2): 216-240.

Kilian, L. (2009). "Not All Oil Price Shocks Are Alike: Disentangling Demand and Supply Shocks in the Crude Oil Market." American Economic Review 99(3): 1053-1069.

Kilian, L. and L.T. Lewis (2011). "Does the Fed Respond To Oil Price Shocks?" The Economic Journal 121(555): 1047-1072.

Kilian, L. and C. Park (2009). "The Impact of Oil Price Shocks on the U.S. Stock Market." International Economic Review 50(4): 1267-1287.

Koopman, S.J., B. Jungbacker, and E. Hol (2005). "Forecasting Daily Variability of the S\&P100 Stock Index Using Historical, Realised and Implied Volatility Measurements." Journal of Empirical Finance 12(3): 445-475.

Laurent, S. (2004). "Analytical Derivatives of the APARCH Model." Computational Economics 24: 51-57.

Lescaroux, F. and V. Mignon (2008). "On the Influence of Oil Prices on Economic Activity and Other Macroeconomic and Financial Variables.” OPEC Energy Review 32(4): 343-380.

Lippi, F. and A. Nobili (2012). "Oil and the Macroeconomy: A Quantitative Structural Analysis." Journal of the European Economic Association 10(5): 1059-1083. 
Maghyereh, A. (2004). "Oil Price Shocks and Emerging Stock Markets. A Generalized VAR Approach." International Journal of Applied Econometrics and Quantitative Studies 1(2): 2740.

Malik, F. and B.T. Ewing (2009). "Volatility Transmission Between Oil Prices and Equity Sector Returns." International Review of Financial Analysis 18(3): 95-100.

Merton, R.C. (1980). "On Estimating the Expected Return on the Market: An Explanatory Investigation.” Journal of Financial Economics 8: 323-361.

Miller, J.I. and R.A. Ratti (2009). "Crude Oil and Stock Markets: Stability, Instability, and Bubbles." Energy Economics 31(4): 559-568.

Park, J. and R.A. Ratti (2008). "Oil Prices and Stock Markets in the U.S. and 13 European Countries." Energy Economics 30(5): 2587-2608.

Pindyck, R.S. (1991). "Irreversibility, Uncertainty, and Investment." Journal of Economic Literature 29(3): 1110-1148.

Rahman, S. and A. Serletis (2011). "The Asymmetric Effects of Oil Price Shocks.” Macroeconomic Dynamics 15(S3): 437-471.

Ratti, R.A., Y. Seol and K.H. Yoon (2011). "Relative Energy Price and Investment by European Firms." Energy Economics 33(5): 721-731.

Sadorsky, P. (1999). “Oil Price Shocks and Stock Market Activity.” Energy Economics 21(5): 449469.

Sadorsky, P. (2011). "Correlations and Volatility Spillovers Between Oil Prices and the Stock Prices of Clean Energy and Technology Companies.” Energy Economics 34(1): 248-255.

Scholtens, B. and C. Yurtsever (2012). "Oil Price Shocks and European Industries." Energy Economics 34(4): 1187-1195.

Vo, M. (2011). "Oil and Stock Market Volatility: A Multivariate Stochastic Volatility Perspective." Energy Economics 33(5): 956-965.

Xekalaki, E. and S. Degiannakis (2010). ARCH Models for Financial Applications. New York: Wiley. 
Figures

Figure 1: Volatility Measures of the Eurostoxx 50 Index, Oil Production Growth Rate, Global Economic Activity and Oil Price Returns

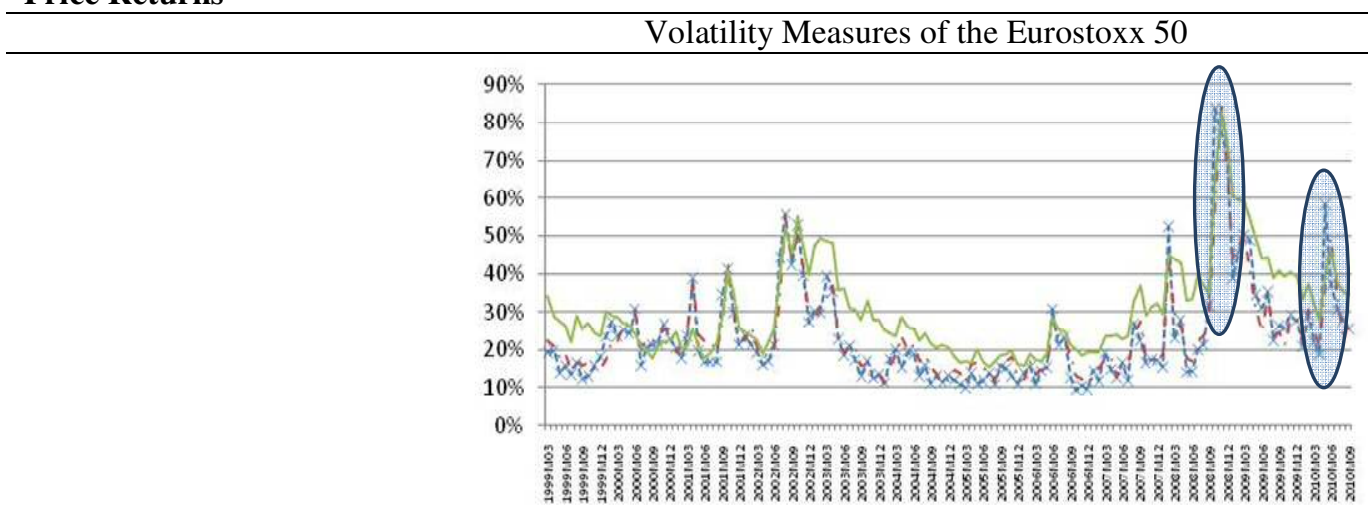

-----RV_STOXX50 -.... CV_STOXX50 -VSTOXX

Oil Production Growth Rate (PROD)

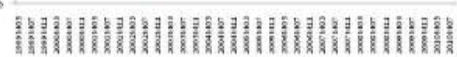

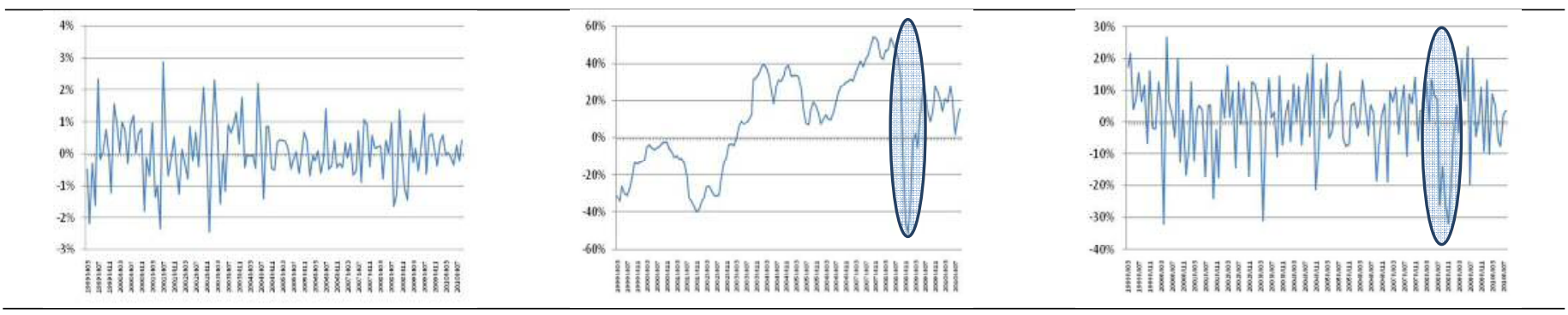

Global Economic Activity (GEA)

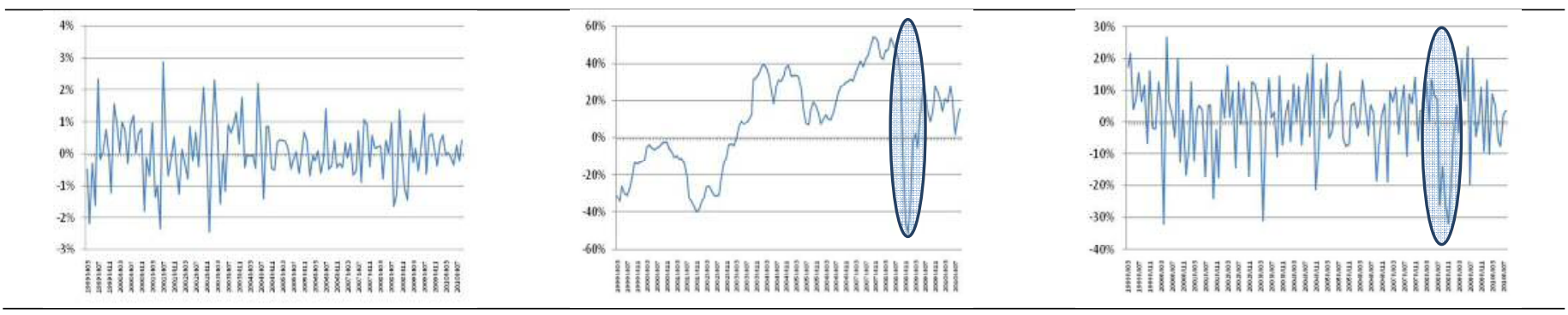

Oil Price Returns (OP) 


\section{Figure 2: Impulse Responses of Current-looking Volatility Measures}
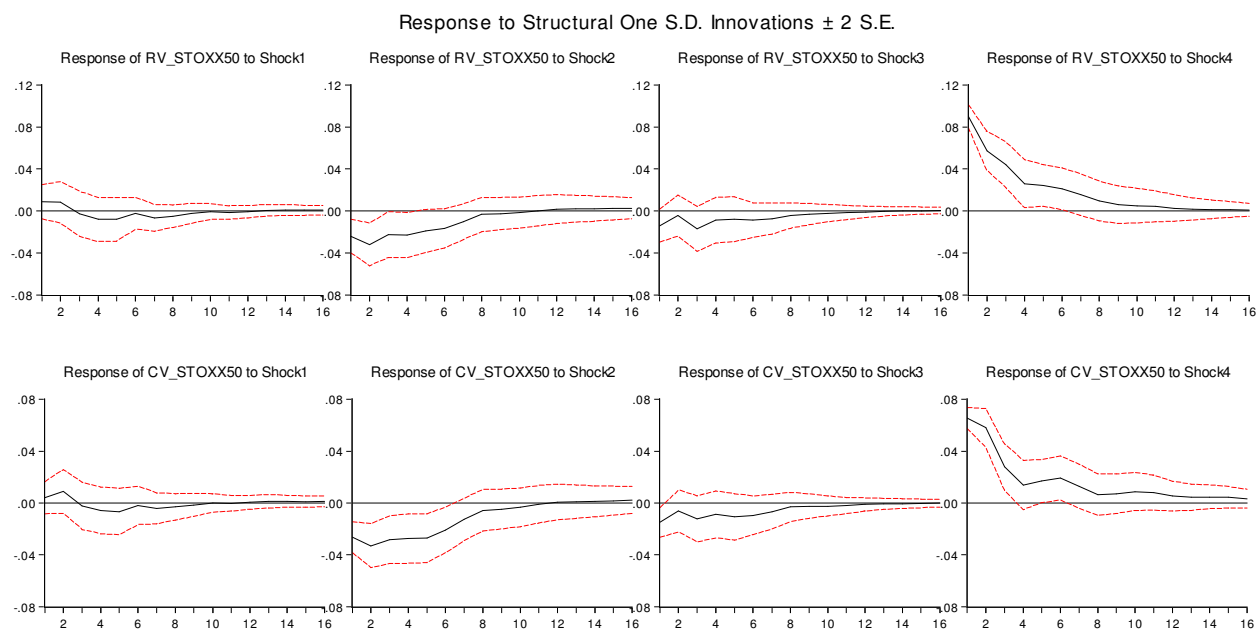

Note: Shock 1 refers to the supply-side shock (PROD), Shock 2 refers to the aggregate demand shock (GEA), Shock 3 refers to the oil specific demand shock (OP) and Shock 4 refers to the volatility shock (VOL). 


\section{Figure 3: Impulse Responses of the Industrial Sectors' Conditional Volatility Measures}
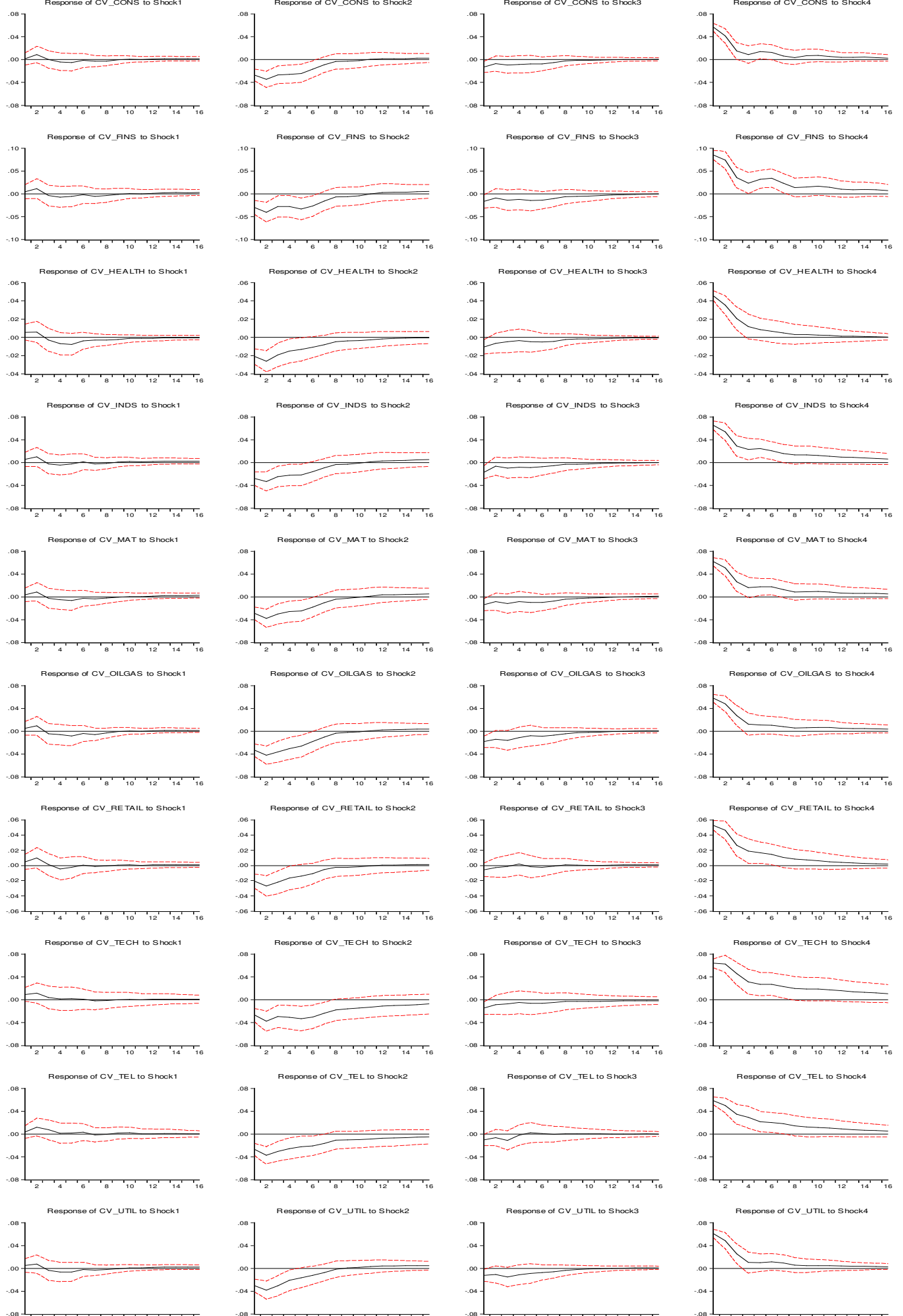

Note: Shock 1 refers to the supply-side shock (PROD), Shock 2 refers to the agregate demand shock (GEA), Shock 3 refers to the oil specific demand shock (OP) and Shock 4 refers to the volatility shock (VOL). The order of the industrial indices is as follows: Consumer Goods, Financials, Health, Industrials, Basic Material, Oil\&Gas, Retail, Technology, Telecommunications, and Utilities. 
Figure 4: Impulse Responses of the Forward-looking Volatility Measure

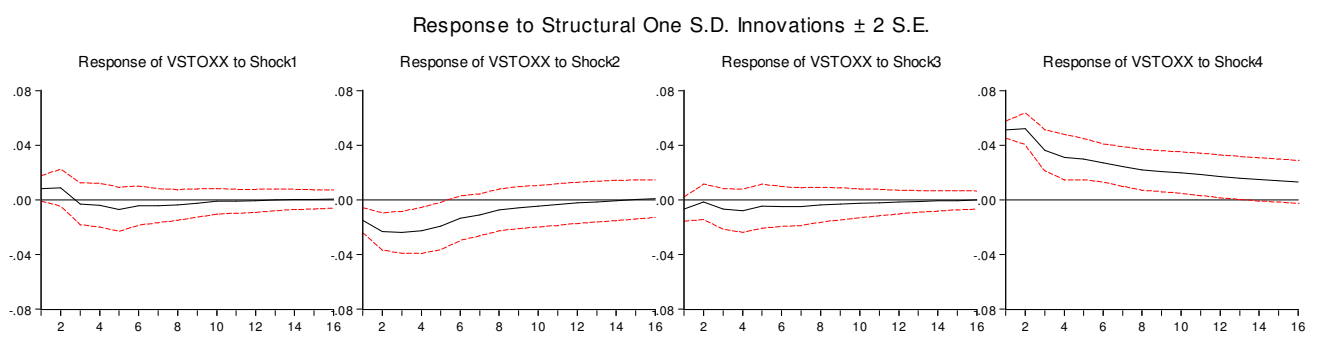

Note: Shock 1 refers to the supply-side shock (PROD), Shock 2 refers to the aggregate demand shock (GEA), Shock 3 refers to the oil specific demand shock (OP) and Shock 4 refers to the volatility shock (VOL). 
Tables

\begin{tabular}{|c|c|c|c|c|c|c|}
\hline & RV_STOXX50 & CV_STOXX50 & VSTOXX & PROD & GEA & OP \\
\hline Mean & $23.41 \%$ & $23.94 \%$ & $30.48 \%$ & $0.06 \%$ & $8.89 \%$ & $1.49 \%$ \\
\hline Max. & $83.55 \%$ & $85.70 \%$ & $82.72 \%$ & $2.89 \%$ & $54.30 \%$ & $26.75 \%$ \\
\hline Min. & $9.38 \%$ & $10.61 \%$ & $15.45 \%$ & $-2.44 \%$ & $-51.30 \%$ & $-32.11 \%$ \\
\hline Std. D. & $13.20 \%$ & $11.57 \%$ & $12.38 \%$ & $0.91 \%$ & $26.19 \%$ & $11.98 \%$ \\
\hline Skew. & 2.038 & 2.170 & 1.448 & 0.045 & -0.259 & -0.643 \\
\hline Kurt. & 8.013 & 9.510 & 5.466 & 3.813 & 2.099 & 3.248 \\
\hline
\end{tabular}

\begin{tabular}{|c|c|c|c|c|c|}
\hline $\begin{array}{l}\text { Volatility } \\
\text { Measure }\end{array}$ & Period & PROD & GEA & OP & VOL \\
\hline \multirow[t]{8}{*}{ CV_STOXX50 } & 1 & $\begin{array}{r}0.318 \\
(1.347)\end{array}$ & $\begin{array}{r}13.389^{*} \\
(5.525)\end{array}$ & $\begin{array}{r}4.334 \\
(3.098)\end{array}$ & $\begin{array}{r}81.959^{*} \\
(6.169)\end{array}$ \\
\hline & 3 & $\begin{array}{r}0.873 \\
(2.256)\end{array}$ & $\begin{array}{r}22.524^{*} \\
(8.408)\end{array}$ & $\begin{array}{r}3.613 \\
(3.472)\end{array}$ & $\begin{array}{r}72.990 * \\
(8.771)\end{array}$ \\
\hline & 6 & $\begin{array}{r}1.238 \\
(3091)\end{array}$ & $\begin{array}{l}30.827 * \\
(10364)\end{array}$ & $\begin{array}{r}4.793 \\
(4901)\end{array}$ & $63.141^{*}$ \\
\hline & 12 & $\begin{array}{r}1.370 \\
(3.687)\end{array}$ & $\begin{array}{c}30.799 * \\
(10.699)\end{array}$ & $\begin{array}{r}5.035 \\
(5.616)\end{array}$ & $\begin{array}{c}62.796^{*} \\
(11.577)\end{array}$ \\
\hline & \multirow[t]{2}{*}{18} & 1.417 & $30.720^{*}$ & 5.004 & $62.859 *$ \\
\hline & & $(3.781)$ & (10.704) & $(5.657)$ & (11.698) \\
\hline & \multirow[t]{2}{*}{24} & 1.469 & $30.872 *$ & 4.988 & $62.671 *$ \\
\hline & & $(3.847)$ & $(10.725)$ & $(5.638)$ & (11.771) \\
\hline \multirow[t]{12}{*}{ RV_STOXX50 } & \multirow[t]{2}{*}{1} & 0.835 & $6.425^{*}$ & 2.197 & $90.542 *$ \\
\hline & & $(1.840)$ & $(4.035)$ & (2.489) & $(4.796)$ \\
\hline & \multirow[t]{2}{*}{3} & 0.924 & $13.082 *$ & 3.188 & $82.806^{*}$ \\
\hline & & $(2.265)$ & $(6.615)$ & $(3.403)$ & (7.596) \\
\hline & \multirow[t]{2}{*}{6} & 1.459 & $16.996^{*}$ & 3.773 & $77.771 *$ \\
\hline & & (3.02) & (8.613) & $(4.492)$ & (9.528) \\
\hline & \multirow[t]{2}{*}{12} & 1.801 & $17.057^{*}$ & 4.092 & $77.050 *$ \\
\hline & & $(3.551)$ & $(8.642)$ & $(5.015)$ & $(10.470)$ \\
\hline & \multirow[t]{2}{*}{18} & 1.816 & $17.175^{*}$ & 4.087 & $76.921 *$ \\
\hline & & $(3.606)$ & $(8.732)$ & $(5.021)$ & (10.659) \\
\hline & \multirow[t]{2}{*}{24} & 1.837 & $17.257 *$ & 4.088 & $76.818 *$ \\
\hline & & $(3.650)$ & $(8.672)$ & $(5.003)$ & (10.783) \\
\hline
\end{tabular}

\begin{tabular}{|c|c|c|c|c|c|}
\hline \multicolumn{6}{|c|}{$\begin{array}{l}\text { Table 3: Variance } \\
\text { Volatilities }\end{array}$} \\
\hline Industrial sector & Period & PROD & GEA & OP & VOL \\
\hline \multirow[t]{10}{*}{ CV_CONSUMER } & 1 & 0.041 & $18.096^{*}$ & 3.970 & $77.892 *$ \\
\hline & 3 & $\begin{array}{r}(1.031) \\
1.031\end{array}$ & $\begin{array}{r}(6.062) \\
32.404 *\end{array}$ & $\begin{array}{r}(3.047) \\
3.616\end{array}$ & $\begin{array}{r}(6.334) \\
62.947 *\end{array}$ \\
\hline & & $(2.495)$ & (8.632) & $(3.428)$ & (8.932) \\
\hline & 6 & 1.206 & $40.208^{*}$ & 4.617 & $53.967 *$ \\
\hline & & (2.794) & $(10.145)$ & $(4.621)$ & (10.142) \\
\hline & 12 & 1.310 & $39.858 *$ & 4.779 & $54.052 *$ \\
\hline & & (3.191) & (10.497) & $(5.144)$ & (10.758) \\
\hline & 18 & 1.450 & $39.705^{*}$ & 4.737 & $54.106^{*}$ \\
\hline & & (3.261) & (10.484) & $(5.102)$ & (10.774) \\
\hline & 24 & 1.561 & $39.838 *$ & 4.737 & $53.863^{*}$ \\
\hline
\end{tabular}




\begin{tabular}{|c|c|c|c|c|c|}
\hline \multirow{13}{*}{ CV_FINANCIALS } & & $(3.331)$ & (10.487) & $(5.079)$ & (10.754) \\
\hline & \multirow[t]{2}{*}{1} & 0.278 & $10.733^{*}$ & 3.151 & $85.836^{*}$ \\
\hline & & $(1.371)$ & (4.926) & $(2.865)$ & $\begin{array}{r}(5.658) \\
77.850^{*}\end{array}$ \\
\hline & \multirow[t]{2}{*}{3} & 0.951 & $18.170^{*}$ & 3.027 & $\begin{array}{r}77.850^{*} \\
(8132)\end{array}$ \\
\hline & & $(2.310)$ & $(7.572)$ & $(3.477)$ & $(8.132)$ \\
\hline & \multirow[t]{2}{*}{6} & 1.042 & $24.285^{*}$ & 4.622 & $70.049^{*}$ \\
\hline & & $(2.851)$ & $(9.679)$ & $(4.907)$ & (10.328) \\
\hline & \multirow[t]{2}{*}{12} & 1.120 & $23.586^{*}$ & 5.066 & $70.226 *$ \\
\hline & & (3.384) & (10.074) & $(5.708)$ & (11.171) \\
\hline & \multirow[t]{2}{*}{18} & 1.280 & $23.621^{*}$ & 4.969 & $70.127 *$ \\
\hline & & $(3.470)$ & $(9.950)$ & $(5.565)$ & (11.229) \\
\hline & \multirow[t]{2}{*}{24} & 1.451 & $24.070^{*}$ & 4.907 & $69.571 *$ \\
\hline & & (3.551) & (9.908) & (5.574) & (11.269) \\
\hline \multirow[t]{12}{*}{ CV_HEALTH } & \multirow[t]{2}{*}{1} & 1.223 & $16.777^{*}$ & 4.077 & $77.922 *$ \\
\hline & & $(2.075)$ & $(5.751)$ & $(2.848)$ & $(6.159)$ \\
\hline & \multirow[t]{2}{*}{3} & 1.375 & $27.397^{*}$ & 3.096 & $68.130 *$ \\
\hline & & (2.394) & $(8.471)$ & (3.292) & $(8.795)$ \\
\hline & \multirow[t]{2}{*}{6} & 3.047 & $31.297^{*}$ & 3.547 & $62.106 *$ \\
\hline & & (3.798) & $(9.882)$ & $(4.035)$ & $(10.242)$ \\
\hline & \multirow[t]{2}{*}{12} & 3.363 & $32.055^{*}$ & 3.933 & $60.648 *$ \\
\hline & & $(4.191)$ & (10.317) & $(4.678)$ & (10.974) \\
\hline & 18 & 3.372 & $32.055^{*}$ & 3.947 & $60.624 *$ \\
\hline & & $(4.265)$ & (10.174) & $(4.760)$ & (11.230) \\
\hline & 24 & 3.372 & $32.055^{*}$ & 3.947 & $60.624 *$ \\
\hline & & $(4.301)$ & $(10.581)$ & $(4.786)$ & (11.384) \\
\hline CV_INDUSTRIAL & 1 & 0.623 & $15.027 *$ & 5.334 & $79.015^{*}$ \\
\hline & & (1.604) & $(5.678)$ & $(3.416)$ & $(6.352)$ \\
\hline & 3 & 1.237 & $22.686^{*}$ & 3.877 & $72.199^{*}$ \\
\hline & & $(2.353)$ & $(8.062)$ & (3.444) & $(8.685)$ \\
\hline & 6 & 1.157 & $26.494^{*}$ & 4.465 & $67.883^{*}$ \\
\hline & & $(2.860)$ & $(9.892)$ & $(4.406)$ & (10.659) \\
\hline & 12 & 1.173 & $25.263^{*}$ & 4.488 & $69.075^{*}$ \\
\hline & & $(3.350)$ & $(9.945)$ & $(4.921)$ & (11.228) \\
\hline & 18 & 1.361 & $25.382^{*}$ & 4.368 & $68.887 *$ \\
\hline & & (3.416) & $(9.788)$ & $(4.858)$ & $(11.212)$ \\
\hline & 24 & 1.512 & $26.065^{*}$ & 4.307 & $68.114 *$ \\
\hline & & (3.488) & $(9.814)$ & $(4.789)$ & $(11.281)$ \\
\hline CV_MATERIALS & 1 & 0.284 & $17.943^{*}$ & 3.921 & $77.850^{*}$ \\
\hline & & (1.354) & $(6.033)$ & $(3.031)$ & $(6.261)$ \\
\hline & 3 & 0.861 & $30.029^{*}$ & 3.800 & $65.308^{*}$ \\
\hline & & $(2.141)$ & $(8.812)$ & $(3.635)$ & (8.973) \\
\hline & 6 & 1.256 & $35.689^{*}$ & 5.061 & $57.992 *$ \\
\hline & & (2.897) & (10.181) & $(5.106)$ & (10.357) \\
\hline & 12 & 1.332 & $34.819^{*}$ & 5.463 & $58.384 *$ \\
\hline & & (3.304) & (10.447) & $(5.935)$ & (11.127) \\
\hline & 18 & 1.494 & $34.907^{*}$ & 5.361 & $58.235^{*}$ \\
\hline & & (3.366) & (10.319) & $(5.880)$ & (11.235) \\
\hline & 24 & 1.654 & $35.189^{*}$ & 5.328 & $57.827^{*}$ \\
\hline & & (3.437) & (10.279) & $(5.484)$ & (11.227) \\
\hline CV_OIL\&GAS & 1 & 0.520 & $23.749 *$ & 7.231 & $68.498 *$ \\
\hline & & $(1.532)$ & $(6.108)$ & (3.595) & $(6.223)$ \\
\hline & 3 & 1.181 & $36.733^{*}$ & 7.064 & $55.020 *$ \\
\hline & & (2.187) & $(8.685)$ & $(4.613)$ & $(8.404)$ \\
\hline & 6 & 1.848 & $43.495^{*}$ & 7.651 & $47.004 *$ \\
\hline & & (3.353) & (10.351) & $(5.731)$ & (9.674) \\
\hline & 12 & 2.094 & $42.875^{*}$ & 8.006 & $47.023^{*}$ \\
\hline & & (3.797) & $(10.630)$ & $(6.231)$ & (10.286) \\
\hline & 18 & 2.151 & $42.849^{*}$ & 7.925 & $47.072 *$ \\
\hline & & (3.794) & (10.497) & $(6.143)$ & (10.319) \\
\hline & 24 & 2.220 & $43.012^{*}$ & 7.895 & $46.871^{*}$ \\
\hline & & (3.834) & (10.404) & $(6.097)$ & (10.306) \\
\hline CV_RETAIL & 1 & 0.754 & $13.153^{*}$ & 1.055 & $85.036^{*}$ \\
\hline & & (1.813) & $(5.311)$ & $(1.729)$ & $(5.790)$ \\
\hline & 3 & 1.640 & $22.100^{*}$ & 0.574 & $75.684^{*}$ \\
\hline & & $(2.847)$ & $(8.121)$ & $(1.923)$ & $(8.359)$ \\
\hline & 6 & 1.698 & $25.006^{*}$ & 0.631 & $72.663 *$ \\
\hline & & $(3.052)$ & $(9.695)$ & $(2.672)$ & $(9.952)$ \\
\hline & 12 & 1.660 & $24.523^{*}$ & 0.626 & $73.189 *$ \\
\hline & & (3.316) & (9.997) & (3.316) & (10.478) \\
\hline
\end{tabular}




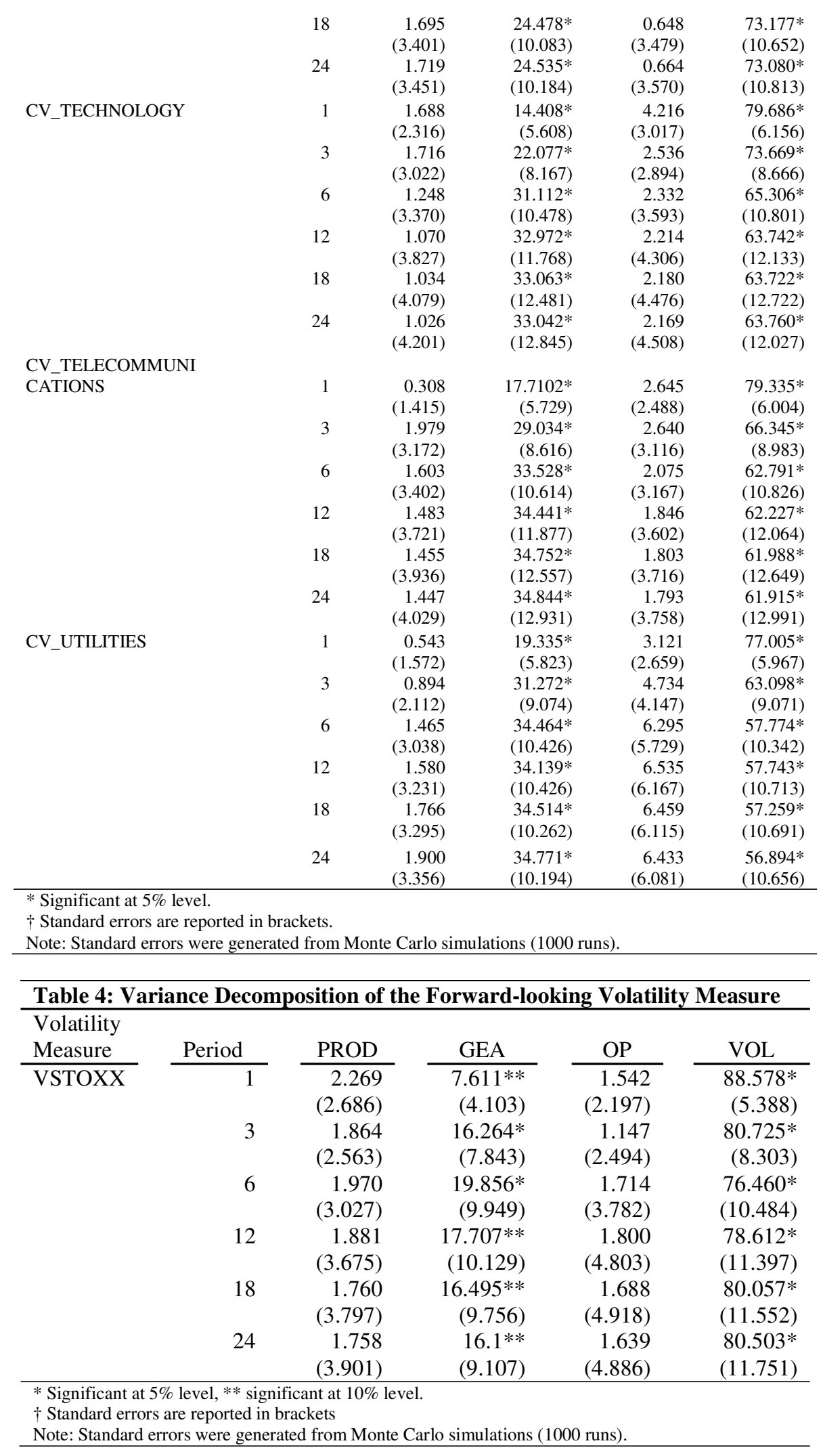

